\title{
PROCEEDINGS OF THE TWENTY-SEVENTH ANNUAL MEETING OF THE AMERICAN SOCIETY FOR CLINICAL INVESTIGATION HELD IN ATLANTIC CITY, N. J., MAY 6, 1935
}

\author{
READ BEFORE SECTION A
}

Physiologic Effects of the Inhalation of Helium with Oxygen on the Mechanics of Respiration. By AlvaN L. Barach, New York, N. Y.

The low density of helium was made use of to provide a respirable gas consisting of 20 per cent oxygen and 80 per cent helium which was one-third as heavy as a comparable air mixture. When prolonged respiratory obstruction was produced in dogs by breathing through narrowed orifices, the effect of helium-oxygen mixture in comparison to air was shown by marked decreases in the inspiratory and expiratory pressures and in the pressure in the pulmonary airways. The latter measurement was obtained by connecting a water manometer to a tube leading from the dog's mouth to a closed respiratory apparatus.

After three hours of breathing air through a narrowed orifice, dogs showed striking increases in intrapleural pressures, marked reduction in the pressure in the pulmonary airways and a progresssively diminished tidal volume. The effect of helium with oxygen at this stage was to reduce the intrapleural pressures, increase the tidal air and to increase the external pulmonary pressure. A stage was produced when a dog could not inhale air but could take in a comparable helium-oxygen mixture.

Studies on the Volume Flow of Blood in the Hands of Cases of Peripheral Vascular Disease. By Norman E. Freeman (introduced by A. V. Bock), Boston, Mass.

The rate of blood flow through the hand, with the temperature controlled, measured by a modification of the plethysmographic technique of Hewlett and Van Zwaluwenburg has been studied. An increase in the volumeflow of blood was found to result from raising the local temperature. The curve obtained under basal fasting conditions was characteristic for the patient from day to day. Immediately after symphathectomy the rate of flow was constant and did not vary with changes in local temperature. Six months later the circulation again was found to change with the local temperature. The logarithm of the rate of flow was a linear function of the reciprocal of the absolute temperature. After release of a circulatory occlusion the excess blood flow above the basal level within certain limits exactly accounted for the amount of deprivation. It is therefore suggested that in the normal hand the circulation is modified through the sympathetic nervous system by the thermal-regulatory needs of the body. After removal of the sympathetic nerves, the blood flow is controlled by the metabolic requirements of the tissues.

In the treatment of Raynaud's disease, active vasodilatation through the calorigenic action of dinitrophenol has proven of value.
In obliterative vascular disease, the power of reflex vasodilatation is lost. Application of local heat increases the discrepancy between metabolic needs and blood supply.

Residual Vasoconstriction from Medulli-adrenal Secretion after Cervicothoracic and After Lumbar Ganglionectomy: An Explanation of the Different Results after Sympathetic Denervation of the Upper and Lower Extremities in Raynaud's Disease. By James C. WhITE, Boston, Mass.

Elliott (1905) first called attention to the fact that the contractile mechanism in the smooth muscle cell becomes abnormally sensitive to adrenaline after its postganglionic neurones have degenerated. Other manifestations of this phenomenon have been demonstrated by the work of Meltzer and Auer (1904), of Hartman, McCordock, and Loder (1923), and of Cannon, Lewis, and Britton (1926). The importance of this effect in man as a cause of failure after sympathetic ganglionectomy for Raynaud's Disease has recently been demonstrated by Smithwick, Freeman, and White (1934). In a second article we showed that this chemical mediation accounts for the ability of the arteries in the rabbit's ear to constrict during insulin hypoglycaemia after the postganglionic neurones have degenerated, and further that this effect is inhibited by inactivation of the adrenal glands.

With the assistance of two Harvard Medical students, I have continued this investigation during the past fifteen months. We have shown that:

1. The residual vasomotor changes in the rabbit's ear, after degeneration of the postganglionic neurones by resection of the superior cervical sympathetic ganglion and division of the remaining vasomotor neurones which run with the sensory nerves (described by Grant, Bland, and Camp, 1932), are in great part due to circulating adrenine and can be largely eliminated by adrenal inactivation (shown by photographs of ear vessels).

2. On the other hand, when the preganglionic neurones are interrupted by stellate ganglionectomy or by division of the upper four anterior thoracic roots, the vessels in the rabbit's ear remain dilated-neither cold, pain, emotion, intravenous adrenaline, nor the adrenine secreted during insulin hypoglycaemia cause any striking degree of vasoconstriction (also shown by photographs of ear vessels).

A comparison of these two experimental procedures reveals in a striking manner the superior degree of vasodilation which is maintained after the preganglionic fibres are cut. This operation interrupts all central efferent vasoconstrictor impulses, but renders the smooth muscle of the arterioles but very slightly sensitive to circulating medulli-adrenal secretion. 
I wish to propose this fundamental difference in reaction as the explanation in man of the frequent poor results after cervicothoracic ganglionectomy and the constant satisfactory results after the lumbar operation. Anatomically the inferior cervical, and first and second thoracic ganglia are known to contain the trophic cells of the great majority of postganglionic neurones to the brachial plexus. On the other hand, as far as the foot is concerned, the lumbar ganglia for the most part contain descending preganglionic fibres. The great majority of postganglionic neurones to the sciatic nerve originate in the three upper sacral ganglia and remain intact after the lumbar operation. Further confirmation of this is given by the skin temperature response to intravenous adrenaline after all four extremities have been denervated (charts). These cases show striking vasospasm in the hands, but only a slight drop in the skin temperature of the toes (temperature charts). We have observed spontaneous vasospasm in the hands on emotional disturbances within ten days after sympathectomy, but no clinical evidence of this in the feet. I believe that sensitization of the denervated smooth muscle in the digital arterioles to adrenine is a better explanation of this phenomenon than local sensitivity to cold (Lewis, 1930), incomplete sympathectomy (Adson, and Leriche and Fontaine, 1933), or the common argument that Raynaud's disease is more severe in the hands than in the feet.

\section{The Significance of Latent Scurvy as an Etiologic Factor} in Rheumatic Fever. By MARK P. Schultz (by invitation), Jules SENDROY (by invitation), and HOMER F. SwifT, New York, N. Y.

Basing the plan upon confirmation of Rinehart and Mettier's observation that infection of scorbutic guinea pigs with Group $\mathrm{C}$ streptococci induced cardiac lesions somewhat resembling those of rheumatic fever, and that only a mild degree of scurvy was requisite, the following course was pursued.

The etiologic relationship of relative vitamin $C$ deprivation to the onset and recurrence of rheumatic fever was studied clinically. By estimating ascorbic acid excretion quantitatively in individuals under controlled intake a method was evolved for testing the relative degree of saturation with vitamin $C$. The vitamin $C$ excretion level was compared with the capillary permeability in patients with rheumatic fever shortly after admission to the hospital and for periods after prolonged high ascorbic acid ingestion.

A second group of rheumatic children, some with active disease, were examined periodically for several months, both with ordinary clinical technique and with testing of capillary permeability. An attempt was made to judge the influence of various habitual diets in respect of vitamin $C$ intake with the tendency to develop rheumatic fever; and one sub-group received large daily doses of ascorbic acid to determine whether this would influence the appearance of relapses.

The results indicate that the occurrence and persistence of rheumatic fever is not exclusively conditioned by the existence of latent scurvy.

Studies of Vitamin $C$ Excretion and Saturation. By JoHn B. Youmans and (by invitation) Marvin B. Corlette, Joseph H. Akeroyd and Helen Frank, Nashville, Tenn.

The daily excretion of vitamin $\mathrm{C}$ in the urine and the degree of retention following the administration of test doses has been studied in a group of presumably normal subjects (hospital staff and personnel) on a diet which was considered to be well balanced and adequate. Similar studies were made on subjects whose diets were suspected of being inadequate in various respects but representative of the diets of a large group of people in this locality. Most of the normal subjects were found to excrete between 15 and $30 \mathrm{mgms}$. of vitamin $C$ daily, amounts which are believed to fall within the range of normal. In them the amount of retention following the administration of test doses indicated a normal degree of saturation. A few supposedly normal subjects excreted less than $15 \mathrm{mgms}$. per day and on test doses showed an apparently significant degree of unsaturation. Many of the subjects whose diets were suspected of being inadequate were found to excrete small amounts of the vitamin.

Relation of Sunlight to Lesions of Pellagra. By JuLian S. Rufrin (by invitation) and David T. Smith, Durham, N. C.

In an analysis of the symptoms in 108 cases of pellagra it was found that the general symptoms were initiated or increased by the development of the dermatitis. Sore mouth or tongue was present in sixteen patients before the development of the dermatitis and in seventyfive after the dermatitis occurred. Diarrhea was present in eight instances before and fifty-two instances after development of dermatitis. Mental disturbances were not present in any of the cases before the dermatitis occurred, but developed co-incidental with or after it in twenty patients.

Unilateral skin lesions were produced by unilateral exposure to sunlight in eleven out of twenty-five patients. None of the fourteen patients who failed to get dermatitis on re-exposure to sunlight developed sore tongue, diarrhea or dementia.

In the eleven patients who did develop dermatitis the stools increased from an average of two per day for the three days prior to exposure to an average of five for the three days immediately after exposure. On reexposure after treatment neither dermatitis nor diarrhea developed.

Sore tongue was increased in eight out of eleven patients who developed dermatitis after exposure to sunlight. Re-exposure after treatment produced neither sore tongue nor dermatitis.

Dementia occurred in three out of eleven patients who developed dermatitis after exposure to sunlight. Two patients died. One who recovered with treatment 
was subsequently exposed to sunlight without any symptoms developing.

Unilateral skin lesions have been produced in pellagra by unilateral exposure. When dermatitis occurs as a result of exposure there is a tendency for the patient to develop diarrhea, sore tongue and sometimes dementia. These symptoms do not occur in patients when they have been exposed to sunlight after receiving adequate treatment.

In evaluating the results of treatment with any specific substance it should be remembered that a considerable number of patients with the classical symptoms of pellagra will recover while on a " $G$ " deficient diet without treatment.

The Prevention of Pellagra by Means of Parenteral Liver Extract Administration. By Austin B. ChInN (by invitation) and Tom Douglas Spies, Cleveland, O.

During the past five years it has been demonstrated in the Medical Clinic of the Lakeside Hospital that the administration of liver extract in repeated large doses is very effective in the treatment of pellagra. Since many of these pellagrins returned to their original environment after leaving the hospital and again imbibed heavily of whiskey, they soon lost desire for food and subsequently pellagra returned. In view of this fact, it seemed worthwhile to determine whether the recurrence of pellagra could be prevented in these individuals in whom it had occurred most frequently. Accordingly, 4 individuals who were among those most frequently admitted to the hospital with pellagra were selected as suitable cases for study. In each instance injection of liver extract was begun immediately after an attack of the disease and was continued for 1 year. (The patients remained in their natural environmental conditions and continued to drink large amounts of whiskey during this period.)

The 4 patients treated as outlined above had a total of 17 hospital admissions during the 9 months just preceding the beginning of this experiment. In contrast, following the beginning of the injections, none of the 4 patients was admitted to the hospital with pellagra during the subsequent 12 months. Interpretation of these observations suggests that the frequent administration of large doses of liver extract aids in the prevention of pellagra.

The Neutralization of Encephalitis Virus (St. Louis, 1933) by Serum. By R. S. Muckenfuss, J. E. Smadel (by invitation) and Elizabetr Moore (by invitation), St. Louis, Mo.

The neutralization test as used with the virus of encephalitis (St. Louis, 1933) depends on adding serum to virus diluted close to the limit of infectivity. As this is done, errors resulting from chance variations in the amount of virus inoculated occur, which reduce the significance of differences in the number of mice dying in individual tests. These factors have been studied and the strain of mice, the strain of virus, and the number of mice used taken into consideration. Virus was neutralized by the serum of over 80 per cent of individuals convalescent from encephalitis in 1933 as well as by the serum of a number of individuals residing in the area. The sera of several individuals recovered from different types of encephalitis in France have been received and none of these neutralized the virus. The significance of these findings is discussed.

\section{Studies on a Filterable Virus Recovered from Cases of \\ Clinical Influenza in Man. By Thомas Francis, JR., and (by invitation) T. P. MAGILL, New York, N. Y.}

A filterable virus was recovered from the pharyngeal washings of influenza patients in Puerto Rico, New York and Philadelphia. The inoculation of the virus into the nasal passages of anaesthetized ferrets or mice produces an experimental disease characterized by a bluish-red edematous consolidation of the lung. In ferrets the disease is usually non-fatal, while most of the infected mice die.

The serum of recovered ferrets mixed with virus and inoculated into the nasal passages of mice prevents the development of the pulmonary lesions, while normal ferret serum has no effect. It has been found that the sera of ferrets recovered from infection with either the Puerto Rico or the Philadelphia strains reciprocally neutralize both strains of virus. In addition, the serum of a horse immunized by Andrewes, Laidlaw and Smith against the British (W. S.) strain of human influenza virus also neutralizes both the Puerto Rico and Philadelphia strains. The serum of swine recovered from infection with swine influenza (obtained from Dr. Shope) fails to neutralize these two human strains of virus. These results indicate that the strains of influenza virus recovered from patients in different parts of the world are immunologically identical, while that of swine influenza differs serologically.

Additional evidence of the identity of the Puerto Rico and Philadelphia strains of virus was obtained by immunization experiments. White mice were vaccinated subcutaneously with living virus obtained from mice or ferrets infected with the Puerto Rico strain of virus. They were then found to be immune to the homologous strain of virus when tested by the intranasal route. When retested with the Philadelphia strain of virus, they were found to be actively immune to this, the heterologous strain, as well.

Furthermore, the serum of influenza patients in New York, taken from the same individuals during the acute and convalescent stages of the disease, was tested against the Puerto Rico strain of virus. The convalescent serum uniformly protected mice, while the serum during the acute illness did not. Control tests were made with the serum of patients in the acute and convalescent stages of lobar pneumonia. In none of these cases did the effect of the convalescent serum on the virus differ from that of the serum taken during the acute stage of pneumonia. 
These results clearly indicate that the virus is causally related to human influenza.

Immunization of Human Subjects with the Specific Soluble Substance of Type VIII Pneumococcus. By Maxwell Finland and (by invitation) James M. RuegSEGGER, Boston, Mass.

The carbohydrate used was prepared from Type VIII pneumococcus by Dr. Rachel Brown. This material is readily soluble. in water or physiologic saline and precipitates the homologous antiserum in a dilution of $1: 4,000,000$. It shows marked cross precipitation reactions with Type III SSS. Dr. Brown's chemical analysis of this material is as follows: nitrogen 0.75 per cent; phosphorus 0.11 per cent; moisture, 5.78 per cent; and ash 6.37 per cent. She has observed that this material produces purpura in mice.

This carbohydrate was given to hospital patients, who had no history of recent pneumonia or other febrile illness. It was given in doses of $0.01 \mathrm{mgm}$. intracutaneously or $1.0 \mathrm{mgm}$. subcutaneously. Studies of the blood were made before and at intervals after the injection for agglutinins and protective antibodies of the serum and for the phagocytic action of defibrinated blood. Type III pneumococci and, in some cases, also Type I pneumococci were used as controls. Each subject developed type specific antibodies, the response being quantitatively similar to that following the recovery from Type VIII pneumococcus pneumonia. The response following the larger dosage did not differ significantly from that following the small intracutaneous injections. No appreciable amount of antibody against Type III, or of Type I, could be demonstrated.

In another group similar experiments were conducted using the Type III carbohydrate. In the subjects who showed a response, this was type-specific and no appreciable amount of Type VIII antibodies developed.

$A$ Correlation of the in vitro Thermal Death Time of the Gonococcus with the Duration of the Artificial Fever in the Treatment of Gonococcal Infections. By S. L. Warren, R. A. BoAK (by invitation, and C. M. CARPEnter (by invitation), Rochester, N. Y.

The in vitro thermal death time has been determined at $41.5^{\circ} \mathrm{C}$. on 95 strains of the gonococcus and found to vary between 6 and 27 hours. Individual patients may harbor several strains differing in their resistance to heat. Artificial fever of from 5 to 17 hours at $41.5^{\circ} \mathrm{C}$. has been given to 118 patients : 64 females, 54 males. Of this number 60 per cent have been clinically and bacteriologically negative for from 3 months to 3 years, while an additional 20 per cent have been negative for from 1 to 3 months.

Each of 11 patients was subjected to a single fever at $41.5^{\circ} \mathrm{C}$., equal in length to the thermal death time of his culture, following which there was an immediate subsidence of all clinical symptoms and a bacteriological "cure." Similar results were obtained in 9 patients when the fever period was $1 / 4$ to $3 / 4$ of the thermal death time, suggesting the assistance of defense factors in the body. Failure in those cases in which the fever was shorter than the thermal death time may be due to the inability of the host to supply the necessary supplemental resistance where the bactericidal effect of the fever has been inadequate.

The Cardiac Output and the Work of the Heart in Hypothyroidism. By Mark D. Altschule (introduced by Herrman L. Blumgart), Boston, Mass.

The cardiac output was estimated in patients with angina pectoris and congestive heart failure at various levels of metabolism before and after total thyroidectomy. Both the acetylene and the ethyl iodide methods were used. They were found to yield identical results. Following operation, when the basal metabolic rate was approximately minus 30 per cent, the cardiac index was decreased to about 1.3, a fall of about forty per cent. This disproportionate decrease in cardiac output was associated with an increase in arteriovenous oxygen difference.

The velocity of blood flow was measured in the same patients by the decholin method. With rare exceptions, changes in the cardiac output were accurately reflected in the velocity of blood flow.

The left ventricular work was calculated by means of the formula of Evans $\left(W=Q V+m V^{2} / 2 g\right)$. The work of the heart was found to parallel the cardiac output. A fall in metabolism of thirty per cent was accompanied by a diminution in the work of the heart of forty per cent, i.e., the work of the heart was decreased more than one would expect merely from the fall in basal metabolism. These observations are of importance in explaining the relief obtained in heart disease following total thyroidectomy.

The Action of Drugs on Myocardial Function in Cardiac and Circulatory Disease. By ISAAC StaRr, JR., and (by invitation) J. S. Donal, A. Margolies and C. J. Gamble, Philadelphia, $\mathrm{Pa}$.

This investigation comprised about 250 estimations of cardiac output on 50 patients in the basal condition.

The rapidly acting drugs (morphine, adrenalin, ephedrine, quinidine, pitressin, choline derivatives and nitrites) were studied as follows. An orthodiagram and electrocardiogram were secured. Duplicate estimations of cardiac output and metabolism, and repeated determinations of blood pressure and pulse rate were made with the subject lying at rest. A drug was then administered and, when its action had manifested itself, the study was repeated.

Digitalis was studied by a repetition of these estimations on different days, together with determinations of vital capacity, venous pressure and circulation time.

Accepting Starling's Law of the Heart as the expression of normal cardiac function, myocardial stimulation may be defined as that condition which permits the heart to do more work per beat in proportion to its size; and depression as the reverse.

Such a conception resolves the discrepancy alleged to exist between the action of digitalis in the clinic and in 
animal experiments. In our cases digitalis causes myocardial stimulation almost without exception. Adrenalin and ephedrine are likewise stimulants. Quinidine and pitressin have little depressant action in therapeutic doses.

Two patients have been studied during angina pectoris and after relief by nitrites.

Effect on Cardiac Output and Cardiac Size of Giving Digitalis to Patients Suffering from Organic Heart Disease without Signs of Congestive Heart Failure. By Harold J. Stewart and (by invitation) J. E. Deitrick, N. F. Crane and W. P. Thompson, New York, N. Y.

One of us ${ }^{1}$ has already reported before this society certain effects upon the circulation of giving therapeutic amounts of digitalis to subjects whose hearts were normal and also to patients suffering from organic heart disease exhibiting signs and symptoms of congestive heart failure. The following facts emerged from those observations: Exposing normal hearts to the actions of digitalis results in decrease in the size of the heart and decrease in the volume of its output of blood per minute. Giving digitalis to certain patients exhibiting signs and symptoms of congestive heart failure when the rhythm was regular or that of auricular fibrillation, resulted in increase in cardiac output and decrease in cardiac size. Since there is one action of digitalis which is common to these two diverse situations, the normal heart and the enlarged heart, namely, an effect on the size of the heart, that is to say a decrease, we were led to the notion that digitalis decreases the size of the heart, and the cardiac output which results depends upon the initial size of the heart; that is, decrease in output in the normal heart and increase in the dilated one. The size of the heart appeared to be pertinent, since we were unable to establish a correlation between decrease in size of heart and decrease in cardiac output and alteration in venous pressure. Results paralleling these had been found to obtain when the observations were made on dogs. 2 In addition, when digitalis was given to dogs in which the hearts were large, the consequence of artificially induced mitral insufficiency, but in which there were no signs of heart failure, the effect was similar to that observed in normal dogs. ${ }^{3}$

It remained, therefore, to observe the effect upon these same functions of giving digitalis to those patients suffer-

1 Stewart, H. J., and Cohn, A. E., J. Clin. Invest., 1932, 11, 917. Studies on the Effect of the Action of Digitalis on the Output of Blood from the Heart. Part 1. The Effect on the Output in Normal Human Hearts. Part 2. The Effect on the Output of Hearts in Heart Failure with Congestion, in Human Beings.

2 Cohn, A. E., and Stewart, H. J., J. Clin. Invest., 1928, 6, 53. The Relation between Cardiac Size and Cardiac Output per Minute Following the Administration of Digitalis in Normal Dogs.

3 Cohn, A. E., and Stewart, H. J., J. Clin. Invest., 1928, 6, 79. The Relation between Cardiac Size and Cardiac ing from organic heart disease who either had never experienced congestive heart failure or who exhibited no signs of congestive heart failure at the time of the exposure to the action of digitalis. Such observations form the basis of this report. To 11 patients, all suffering from rheumatic heart disease, digitalis American Heart Association 1.6 to $1.8 \mathrm{gm}$. was given within 24 hours. The rhythm of the heart was regular in all subjects. Measurements of cardiac output were made by the acetylene method of Grollman, of arm to tongue circulation time by the intravenous injection of decholin, of venous pressure by the direct method, and of cardiac size from the measurement of the cardiac shadow in 2 meter $x$-ray photographs. Observations were made before and at 24 hours after as well as at later intervals after giving the drug. All observations were made with the patients in a basal metabolic state. The doses of the drug were given at the same time of the day to all subjects, and the observations were made at identical times.

The results fell into 3 groups. 1. In certain of the patients the effect of giving digitalis was to decrease cardiac size and cardiac output, and to increase circulation time; venous pressure did not follow any consistent pattern; that is to say, the effect was similar to that observed in giving the drug to normal individuals.

2. In others the effect was to decrease cardiac size and to increase cardiac output and to decrease circulation time; the venous pressure was not significantly altered; that is to say, a result similar to that observed in patients suffering from congestive heart failure.

And finally (3) in certain instances, the cardiac size, cardiac output, and circulation time and venous pressure remained unchanged, although the alterations of the $T$ waves of the electrocardiogram showed evidence of one digitalis effect on cardiac muscle.

It appears therefore that if digitalis alters the size of the heart, change in its output occurs; its volume output decreases if the heart was beforehand not dilated and it has been made a smaller pump; on the other hand its output increases if the dilated heart has by becoming smaller been made a more appropriate size. The balance of factors which come into play in those instances in which the circulatory functions which were measured showed no alteration, is not known. In certain instances when digitalis was given and the cardiac output decreased, the patients became cyanotic and dyspneic. It appears therefore that patients without obvious heart failure, patients in a similar functional classification as far as clinical data could be evaluated, behave in an unpredictable way on taking digitalis.

The cardiac volume was plotted against the gram meters of work of the left ventricle per beat. Four patients fell into the zone of threatened heart failure according to the correlation demonstrated by Starr,4 Fig. 2, but these

Output per Minute Following the Administration of Digitalis in Dogs in Which the Heart is Enlarged.

4 Starr, Isaac, Jr., Collins, L. H., Jr., and Wood, F. C., J. Clin. Invest., 1933, 12, 13. Studies of the Basal Work and Output of the Heart in Clinical Conditions. 
four did not fall into a single group with respect to the effect of digitalis but fell into the three groups; so that a distinction could not be made on this basis. One correlation did arise, however: in three of these four patients in whom the cardiac size was altered by digitalis, whether the cardiac output was increased or decreased, they moved up into the zone of normal cardiac function, in which the cardiac work became commensurate with the cardiac size.

Conclusions: It appears that alterations of the cardiac output following the giving of digitalis are associated with alterations of cardiac size. When alterations of size failed to occur, the cardiac output remained unchanged.

It is demonstrated anew that decrease in cardiac size and decrease in cardiac output was not associated with decrease in venous pressure. That is to say, additional evidence is presented that decrease in cardiac output which follows the giving of digitalis in certain instances is not a consequence of fall in venous pressure but, so far as one can ascertain, is a consequence of decrease in size of the heart by the action of digitalis on it.

Intermittent Blood Flow in the Capillaries of Human Skin. By James Bordeley, III, Max H. Grow (by invitation) and William B. Sherman (by invitation), Baltimore, Md.

The skin over the tibia of normal human subjects has been observed microscopically. Room temperature has been controlled and the skin-area under observation has been supported horizontally at heart level. Using a magnification of $90 \times$ to $150 \times$ it has been possible to see blood flow in capillary loops, in venules and, occasionally, in arterioles. The flow of corpuscles in many capillary loops has been found to be intermittent in character. Intermissions may be only momentary but frequently last for periods of several minutes or longer. When flow ceases the capillary usually contains motionless corpuscles and remains visible; only occasionally does it disappear from view. Alternating progression and cessation of corpuscular flow has been observed in single capillaries over periods as long as one hour. When flow is observed simultaneously in two or three neighboring capillaries it is generally found that the periods of intermission do not coincide.

We conclude that the blood flow in the capillaries of normal human skin may show intermittency similar to that described for the capillaries of various organs of lower animals (kidney, muscle, lung, etc.). This conclusion differs from that which Lewis 1 derived from his observations upon the skin of the hand and forearm.

Chemical Studies in Addison's Disease. By J. S. L. Browne and Eleanor M. Venning (introduced by J. C. Meakins), Montreal, Canada.

Studies on sodium, potassium, calcium and nitrogen balances have been made on three cases of Addison's disease over a period of months: and the effect of ad-

\footnotetext{
1 T. Lewis, Heart, 1926, 13, 1.
}

ministration of sodium chloride by mouth and of cortical (Eschatin) and pituitary adrenotropic extracts studied. There is some indication that the extracts used influence the potassium balance. The effects of glucose, given orally or intravenously, and of adrenalin and small doses of insulin on the blood sugar were investigated in some cases. Sodium chloride administration sometimes depressed the blood urea below the normal level, the excretion of ingested urea was then delayed. One case died after a mild pharyngitis, he was in negative sodium, potassium and nitrogen balance, and the sodium concentration in the urine decreased in the two weeks between the infection and death. During collapse the sodium, urea and volume of the blood were normal and the blood pressure rose; the blood sugar decreased to $20 \mathrm{mg}$. per cent. It is felt that a disturbance of carbohydrate metabolism in Addison's disease is not only a secondary terminal event but can act in some cases separately from the mineral-water disturbances to cause collapse.

The Relief of Human Myxoedema by an Artificial Human Protein. By Willia M. Salter, Boston, Mass. Thyroxin contributes only about one-third of the iodine in thyroglobulin extracted from human glands surgically excised in Boston. As previously reported to this society, however, all of this thyroglobulin iodine is equally potent in relieving myxoedema. Although pure di-iodotyrosine is calorigenically inert, yet, paradoxically, it apparently contributes the major part of the metabolic potency when combined in the thyroglobulin molecule.

When this human thyroid protein is digested with pep$\sin$, it is possible to remove the thyroxin fraction. The remaining solution of di-iodotyrosine peptone is free of protein and can be filtered under pressure through a standard "Cellophane" membrane. Under appropriate chemical conditions, this material may be subjected to peptic synthesis, thus reversing the original digestion process.

The artificial protein resulting from this enzymic synthesis resembles natural thyroglobulin. It fails to dialyze through the standard "Cellophane" membrane. Its iodine content varies from 0.2 per cent to 0.3 per cent. It was found clinically 1 to relieve myxoedema as effectively as thyroglobulin in equivalent-iodine dosage. Thyroglobulin from primary hyperplastic glands and from multiple colloid adenomatous goitres yielded similar artificial proteins.

This type of hormone synthesis promises to explain the high activity of thyroid substance. It also suggests that enzymic synthesis may play an important rôle in the economy of this endocrine.

A Thyroid Derivative with Greater Calorigenic Activity than Thyroxine. By W. O. Thомpson and (by invitation) S. B. Nadler, P. K. Thompson and S. G. TAYLOR, III, Chicago, Ill.

By proteolytic digestion of desiccated thyroid, a fraction has been obtained which, when injected subcuta-

1 Assays were done in the thyroid clinic of the Massachusetts General Hospital. 
neously, possesses greater calorigenic activity per milligram of iodine than thyroxine given by the same route. The following observations are important in the interpretation of this finding: 1. Per milligram of iodine, desiccated thyroid is more active than the amount of thyroxine in it would indicate. 2. Experiments in man have failed to show that 1-thyroxine possesses greater activity than d-thyroxine (Salter, Lerman and Means) or that a comparatively simple peptide of thyroxine with a nitrogen: iodine ratio of $0.48: 1$ possesses any greater activity than racemic thyroxine. 3 . The method used to extract thyroxine from the thyroid (heating with alkali) destroys from two-thirds to four-fifths of the gland's activity, whereas it has little effect on thyroxine itself. These data suggest: (1) that the activity of thyroxine may be enhanced by its natural combination, and (2) that the compound which possesses this enhanced activity has a more complex molecule than the thyroxine peptide referred to.

The Use of Gonadotropic Anterior Pituitary Extract in Women Who Flow without a Premenstrual Endometrium. By Elmer L. Sevringhaus, and (by invitation) Ralph E. Campbell and Frederick L. Hisaw, Madison, Wisconsin.

Study of menstrual irregularities has convinced us that there is no typical history associated with any one type of disturbance in the ovarian and uterine cycles. Endometrial biopsies have facilitated definite diagnoses. In some patients there was repeatedly a bleeding from an estrin type of endometrium, or anovulatory menstruation. This might occur with regular or irregular cycles.

Since the obvious deficiency in such patients is the failure to form a functional corpus luteum, we have employed the anterior pituitary extracts described and prepared by Hisaw and Fevold. They found that use of this material subcutaneously stimulated development of Graafian follicles, but that luteinization in the monkey was obtained only after the intravenous administration of the same mixed pituitary extract. We therefore tried this material intravenously in selected patients, at 14 days after the beginning of a flow. Treatment was given once monthly, with doses ranging from 0.5 to $1.0 \mathrm{cc}$. of the extract such as is now on the market. ${ }^{1}$

We can report that in at least four such patients we have secured indubitable evidence of the formation of a corpus luteum with typical progestational endometrium. In four others this did not follow although there was clinical benefit. These latter cases came to laparotomy shortly after treatment, and it was found that they had large follicular cysts. In two cases these cyst walls showed evidence of beginning luteinization, but not complete corpus luteum formation. The results accord with the findings of Hisaw in monkeys. He was unable to cause luteinization after he had stimulated the ovaries

1 For the supply of the pituitary material we are indebted to Dr. A. E. Meyer, of Chappel Bros. Laboratories, Rockford, Ill. to the extent of producing follicular cysts of large size We believe this is the first evidence of the production of corpora lutea in women by the use of anterior pituitary extracts.

The Pathological Physiology of the Menopause. By Fuller Albright, Boston, Mass.

This study consists of data which enable one to plot the pituitary prolan A and estrin contents of the urine of patients at the menopause against the number of hot flashes. The data were collected before, during and after treatment with estrin. Certain deductions are made. In the first place the menopause is a "primary ovarian amenorrhoea" as opposed to lack of ovarian function secondary to pituitary hypofunction, because with the under-production of estrin, there is over-production of prolan A. The next question, the one which this study especially concerns itself with, is which of these hormonal abnormalities, if either, is the cause of the systemic symptoms. Evidence is brought forth that lack of estrin is not the cause of the hot flashes; however, the evidence is convincing that estrin therapy stops the hot flashes; estrin therapy also decreases the prolan $\mathrm{A}$ over-production; the evidence is not altogether conclusive, however, that the hot flashes are directly correlated with the excessive prolan A production. Certain implications as to treatment are made.

Respiratory Function in the Respiratory Neuroses. By Ronalp V. Christie, Montreal, Canada.

In the past $2 \frac{1}{2}$ years, thirty-five cases suffering from one or other form of respiratory neurosis have been collected from the patients passing through the Royal Victoria Hospital. The identification and classification of these cases has been facilitated by the taking of spirometric tracings of the tidal air and of various forms of respiratory gymnastics. In some cases it was only by means of such tracings that a final diagnosis of a respiratory neurosis could be made. The two main groups which could be defined by this technic were: $(a)$ the anxiety neuroses, which include cases of effort syndromes and so-called war neurasthenia and $(b)$ the conversion hysterias which in their later stages give rise to "hyperventilation tetany." An analysis of haemo-respiratory exchange in selected cases from each of these two groups is of interest in showing the physical changes which may result from such a functional disturbance.

Carotid Sinus Syncope and its Bearing on the Mechanisms of Unconscious State and Convulsions. By Eugene B. Ferris, Jr. (by invitation), and Richard B. Capps (by invitation) and Soma Weiss, Boston, Mass.

Weiss and Baker have demonstrated the relationship existing in man between a hypersensitive carotid sinus reflex and certain types of syncope and convulsions. They have differentiated three types of syncope of carotid sinus reflex origin. Prolonged cardiac asystole with a secondary fall in the arterial pressure, and a primary re- 
flex vasodepressor reaction without cardiac inhibition, respectively, have played a primary rôle in two types. Cerebral anoxemia was a precipitating factor in both of these types.

This study presents the results of an investigation of the third, and hitherto obscure, type of syncope, as manifested in 25 patients observed in spontaneous and in induced attacks. The following observations indicate the specific sensitivity of the sinus: 1 . Pressure over the sinus induced attacks in as short a time as 4 seconds. 2. Sudden increase in the intracarotid pressure resulting from the release of a compressed carotid artery below the sinus, induced mild symptoms. 3. Stimulation of the sinus with sodium cyanide resulted in symptoms. 4. Occlusion of the carotid artery below the sinus failed to induce symptoms. 5. Novocainization of the sinus abolished the induced reactions. 6. Surgical denervation of the sensitive sinus abolished both the spontaneous and the induced symptoms in 8 patients for as long as 14 months.

The clinical manifestations cannot be explained on the basis of changes in the systematic hemodynamics during attacks, as no fall in blood pressure nor cardiac slowing occurred. The cerebral circulation during and between attacks was studied with the aid of the Gibbs blood-flow recorder, as well as with blood gas measurements. Observations were also made on the effects of strychnin, digitalis, oxygen, carbon dioxide, acetyl- $\beta$-methylcholin, caffein, amyl nitrite, ephedrin, adrenalin, pilocarpin and atropin.

The interpretation of the observations in this study is that the manifestations were brought about not by generalized cerebral anoxemia, but by nervous impulses originating in the sinus and acting upon a localized area of the midbrain regulating consciousness. The observations bear pertinently on the reflex origin of unconscious states and on the mechanism of the tonus of autonomic nerve centers.

\section{The Incidence and Significance of Minute Beta Hemolytic}

Streptococci. By Perrin H. LoNg and (by invitation)

Eleanor A. Buiss, Baltimore, Md.

Minute beta hemolytic streptococci have been isolated from the throats of 87 per cent of 66 individuals ill with glomerular nephritis. It is noteworthy that these organisms occurred with much greater frequency in those individuals whose disease had had an acute onset than in those in which the onset of the nephritis was insidious. These minute organisms were isolated from the throats of 50 per cent of individuals suffering from rheumatic (fever) infection. In both glomerular nephritis and rheumatic infection more throat cultures were positive for minute beta hemolytic streptococci than for ordinary beta hemolytic streptococci. The incidence of these minute organisms in the throats of normal human beings and in those of patients ill with diseases other than nephritis or rheumatic infection was less than that of ordinary beta hemolytic streptococci.

When tested by Lancefield's method these minute organisms fall into three antigenic groups which are different from those described for ordinary beta hemolytic streptococci. They produce a filterable hemolysin which differs from that already described for ordinary beta hemolytic streptococci. The sera of certain normal individuals contained agglutinins in low titer for these organisms. The sera of patients suffering from glomerular nephritis beginning with an acute onset, streptococcal sore throat and rheumatic infection contained agglutinins in a relatively high titer against these minute organisms. In certain instances recovery from these diseases was paralleled with a marked increase in the agglutinin titer against these minute organisms. The sera of normal carriers of minute hemolytic streptococci showed a normal agglutinin content. In view of the well known association of beta hemolytic streptococcal infections of the throat with the onset and progression of acute glomerular nephritis and rheumatic (fever) infection we feel that these findings assume an added importance.

The Effect of Splanchnic Nerve Resection and Sympathetic Ganglionectomy in a Case of Paroxysmal Hemoglobinuria. By A. Carlton ERNSTENe and (by invitation) W. James Gardner, Cleveland, Ohio.

In a patient with paroxysmal hemoglobinuria, hemoglobinuria regularly followed the application of ice packs from the feet to the level of the anterior superior spine of the ilium or xiphoid process. After spinal anaesthesia, ice packs did not cause hemoglobinuria. Novocaine block of both lumbar sympathetic chains did not prevent the production of hemoglobinuria by ice packs. For more than one month after resection of the left splanchnic nerves and removal of the first lumbar ganglion, ice packs failed to induce hemoglobinuria ; and after a similar operation on the right side, ice packs were ineffective for nearly six months. Subsequent complete lumbar ganglionectomy and cervico-dorsal ganglionectomy did not prevent the production of hemoglobinuria by ice packs although packs of somewhat longer duration were necessary after the operations. Increased tolerance to cold is demonstrated further by a great reduction in the frequency of spontaneous attacks. One year ago short exposure to ordinary winter weather invariably induced hemoglobinuria, while during the present winter there have been but three attacks in spite of prolonged periods of exposure.

The Donath and Landsteiner reaction was consistently positive before the first operation but became negative after that operation and has remained so.

The observations indicate that the sympathetic system plays an important rôle in the pathogenesis of paroxysmal hemoglobinuria.

\section{READ BEFORE SECTION B}

Metabolic Studies of the Change in Body Electrolyte and Distribution of Body Water Induced Experimentally by Deficit of Extracellular Electrolyte. By DaNIEL C. DARRow and (by invitation) HERMAN YANNET, New Haven, Conn.

Dogs were subjected to losses of extracellular electrolyte by a technique previously described. About $100 \mathrm{cc}$. 
per kilogram of body weight of 5 per cent solution of glucose was injected into the peritoneal cavity and after considerable electrolyte had diffused into the solution as much of the peritoneal fluid was removed as was possible with a trocar. The dogs were fed a food containing little $\mathrm{Na}, \mathrm{K}$ and $\mathrm{Cl}$, and the serum and whole blood were analysed for electrolyte, and the balance of electrolyte determined over a number of days on the excreta.

The data on the blood demonstrate that deficit of extracellular electrolyte (chiefly $\mathrm{Na}$ and $\mathrm{Cl}$ ) produces a considerable decrease in the volume of the plasma and extracellular fluid. The loss of extracellular fluid is explained not by loss of water from the body but rather by shift of extracellular water into the cells. The blood studies show that this disturbance in the distribution of body water persists until the deficit of $\mathrm{Na}$ and $\mathrm{Cl}$ is replaced. The body apparently does not compensate for decrease in extracellular electrolyte by decrease in intracellular potassium. Such losses of potassium as occur are accounted for by losses of nitrogen. Furthermore, electrolyte concentration remains reduced since the kidneys fail to excrete water in order to adjust electrolyte concentration. The dogs show persistent signs and symptoms of dehydration which is not accounted for by any loss of water but rather by the disturbance in the distribution of body water brought about by the deficit of extracellular electrolyte.

Magnesium Balances in Health and Disease. By DoRothy M. Tibbetts (by invitation) and Joseph C. Aub, Boston, Mass.

The normal partition of magnesium excretion on a constant diet has been established. As with calcium, magnesium is excreted more in the feces than in the urine. The addition of more magnesium in the diet increased excretion by both channels, but predominantly in the fecal excretion. It also obviously increases urinary calcium excretion.

The production of an acid intake by the use of ammonium chloride and also the addition of various phosphates did not usually affect magnesium output in urine or feces. The effect of hyperparathyroid disease and of parathormone has been carefully studied, and it is clearly demonstrated that calcium and magnesium metabolism are not similarly affected. Thus, magnesium excretion remains comparatively constant, while calcium metabolism varies enormously.

It is, therefore, clear that magnesium metabolism is not markedly affected by the agents which influence calcium exchange.

The State of Calcium in the Blood in Nephritis and Uremia. ${ }^{1}$ By FrankLIN C. MCLean and LouIs LEITER, Chicago, Ill.

When the phosphate concentration of the blood is augmented in normal animals there is, first, formation of a

\footnotetext{
1 This work has been aided by a grant from the Josiah Macy, Jr., Foundation.
}

colloidal calcium-phosphate complex, resulting in a fall in $\mathrm{Ca}^{++}$concentration; and, second, removal of the complex from the blood, resulting in a fall in total calcium. ${ }^{2}$

When $\mathrm{Ca}^{++}$concentrations as observed by the frog heart method are compared with those calculated from total calcium and total protein, in cases of uremia with hyperphosphatemia, no indication of accumulation in the blood of a calcium-phosphate complex is found. In nearly every case, however, in which the inorganic phosphate concentration of the serum exceeds 3.0 millimols per liter the $\mathrm{Ca}^{++}$concentration is depressed below the normal level, associated, in some cases, with tetany. No satisfactory further correlation between the phosphate level and the $\mathrm{Ca}^{++}$concentration has been found.

These findings are best explained, qualitatively, by assuming that a colloidal calcium-phosphate complex is formed in the blood, in the presence of hyperphosphatemia, and is removed from the blood as rapidly as formed. The quantitative relationships involved are not as yet clear.

The Volume of the Extracellular Fluids. By P. H. LAvieTes, (by invitation) J. BourdiLLoN and (by intation) J. P. Peters, New Haven, Conn.

The extent of diffusion of sucrose, thiocyanate and inorganic sulfate in man and the time required for its completion have been determined. All three substances can be recovered quantitatively from the urine. Of the three, SCN alone enters red blood cells, and even this probably enters no other cells in the body. In normal subjects, sucrose and inorganic $\mathrm{SO}_{4}$ diffuse through approximately 20 per cent of the body weight; SCN, through 22 per cent. This portion probably represents extracellular fluids of the body and changes when those fluids are expanded or contracted by varying the salt intake. One and one-half hours is sufficient for complete diffusion of sucrose; $\mathrm{SCN}$ and $\mathrm{SO}_{4}$ diffuse more rapidly. In 4 patients with advanced renal failure without edema, extraordinarily high values were attained, probably because extracellular fluid had replaced wasted cellular tissue and fat.

Studies of Hypoproteinemia and Proteinuria. By HARold A. Bulger, St. Louis, Mo.

Hypoproteinemia in nephritis usually continues and may remain relatively constant even with considerable nitrogen storage over a long time. That protein is not lost into extra-vascular fluids and then rapidly broken down has been indicated by a study of the amino acids of these fluids. The amino acid content is continually about the same as that of serum. An increased protein intake, although attended by an increased nitrogen storage, results in a greater proteinuria and unchanged plasma protein level. Indirect evidence of defective protein formation is presented. This with the variability of proteinuria is pictured as explaining the continued hypoproteinemia. Factors influencing proteinuria are there-

${ }^{2}$ McLean, F. C., and Hinrichs, M. A., Proc. Am. Soc. Biol. Chem., 1935 (in press). 
fore important therapeutic considerations. Urea administration, like comparable amounts of protein, may result in considerable nitrogen storage but increased proteinuria. Diuresis of alkaline potassium salts results in increased proteinuria. Sodium bicarbonate may cause an increase in protein excretion. Mercurial diuretics may increase the protein loss. The rise in nitrogen metabolism from insufficient calories was attended by greater proteinuria.

Elimination of Heat by Evaporation of Water from the Lungs in Heart Failure. By J. M. SteELe, New York, N. Y.

It has been shown that during heart failure the surface temperatures of certain individuals are low while after recovery they rise (Steele and Cohn). If identical environmental conditions prevail less heat is radiated from the surface before than after recovery. Evidently heat is lost elsewhere. The result of this study suggests that the lungs redress the balance.

The patients in a basal state were examined under relatively constant environmental conditions. They breathed into a Benedict-Roth spirometer supplied with a rotary pump. Water and $\mathrm{CO}_{2}$ eliminated by the lungs were taken up by $\mathrm{CaCl}_{2}$ and soda lime respectively and weighed. Consumption of oxygen was measured volumetrically. The tests lasted 12 minutes. Duplicate measurements differed by less than 5 per cent. The accuracy of the apparatus was within 1.2 per cent (alcohol check lamp).

In two normal persons and in two with arterial hypertension heat eliminated by vaporization of water from the lungs was found to vary from 9.5 to 12 per cent of the total heat produced by the body. These figures agree well with those of Benedict and Benedict (1926). In three cardiac cases, in which the surface temperatures were shown to be low during heart failure, the percentile values were thrice normal ( 30 to 35 per cent) and fell to normal (10 to 15 per cent) with recovery. In the fourth case, one of recent mild heart failure, the fall was not so marked (from 16 to 11 per cent), and the surface temperatures were not low.

It is concluded that loss of water from the lungs increases during heart failure to a greater extent than does the general metabolism, acting apparently as a substitute for radiation from the surface of the body.

Effects of Amino-acids on the Creatine Content of Rabbit Heart Muscle. By George Decherd (by invitation) and George Herrmann, Galveston, Texas.

The isolated rabbit heart perfused with oxygenated Ringer-Locke solution will fail in 6 to 10 hours even to artificial stimulation and in spite of the removal of the $\mathrm{CO}_{2}$ from the perfusate and maintenance of the $\mathrm{pH}$ at the normal alkaline level. The creatine content of the heart muscle dropped when the $\mathrm{pH}$ of the perfusion fluid was allowed to fall below 7.3-7.5. Twenty-three normal hearts perfused for one minute to wash out the coronary system contained an average of $154 \mathrm{mgm}$. per cent (143$168 \mathrm{mgm}$. per cent) of creatine. Fifteen hearts perfused for one to eight hours beating spontaneously, or stim- ulated at a rate of 60 per minute to exhaustion, showed 100-151 with an average of $123 \mathrm{mgm}$. per cent of creatine. Dried weight values were calculated for all hearts and were found to parallel the moist weight values. Glycocoll added to the perfusate in $100 \mathrm{mgm}$. per cent augmented the action of the hearts in 21 experiments but had no influence on the creatine content, which showed values of 103-159 with an average of $134 \mathrm{mgm}$. per cent. Glutamic acid was toxic in $100 \mathrm{mgm}$. per cent in the perfusate but, after $10 \mathrm{mgm}$. per cent was added to the perfusate, 4 hearts contained 108-134 with an average of $116 \mathrm{mgm}$. per cent of creatine. Arginine in $10 \mathrm{mgm}$. per cent was added in a similar series and gave 100-126, average $115 \mathrm{mgm}$. per cent; aspartic acid in $10 \mathrm{mgm}$. per cent in the perfusion fluid had little effect with creatine values of 108-148 with an average of $134 \mathrm{mgm}$. per cent; methyl-guanidine in $10 \mathrm{mgm}$. per cent was also without definite effect, since levels of 126-150 with an average of $138 \mathrm{mgm}$. per cent were obtained; while with creatine itself the results were $125-161$ with an average of 138 mgm. per cent. d-1-Alanine, however, in 50 or $100 \mathrm{mgm}$. per cent in the perfusate seemed definitely to raise the creatine content, the results in 20 experiments being 136-205 with an average of $166 \mathrm{mgm}$. per cent. This amino-acid therefore appears to act as a sparer of creatine in the rabbit heart muscle under the conditions of our experiments. Myocardial infarction, regardless of the perfusate used, caused a very sharp drop in the creatine values, these being 51-99 with an average of 79 mgm. per cent.

\section{The Effect of Exercise on the Blood Sugar of Patients with Diabetes Mellitus With and Without Insulin. By Alexander Marble and (by invitation) Rachel $M$. Smith, Boston, Mass.}

Exercise along with diet and insulin is an accepted part of the present-day treatment of diabetes. Its ability to lower the blood sugar of patients receiving insulin is well recognized. That this beneficial effect may not occur in an individual who is receiving an inadequate amount of insulin is, however, not generally appreciated. Serial determinations of the capillary blood sugar of young diabetic patients were made in the early morning before insulin and breakfast. Suitable control curves were obtained with the patient at rest, with and without insulin, and with the patient exercising with insulin. All tests done without previous insulin were uniform in showing an unmistakable rise in the blood sugar following five or ten minute periods of moderate exercise (running or using a rowing machine). This occurred even though the initial blood sugar was as low as 0.16 per cent as it was in one instance. The conclusion is drawn that in order for exercise to exert its maximum benefit in diabetic patients there must be an adequate supply of insulin either of endogenous or exogenous origin.

The Effect of Crude Lipoids on Antigenic Function. By Franklin M. Hanger, New York, N. Y.

Numerous workers have demonstrated that the physical state of an antigen plays an important rôle in the 
degree of antibody production. For example, egg albumin adsorbed on alumina or calcium phosphate is more effective as an antigen than an equal amount of aqueous egg solution. This may be due in part to the avidity of the reticulo-endothelial system for particulate matter.

Crude lecithin in non antigenic; it is, however, a most effective emulsifying agent and when injected into the tissues is readily taken up by clasmatocytes and other reticulo-endothelial cells. Experiments were devised to determine if this substance, when mixed with antigens of various types, can modify the immune response.

$.45 \mathrm{mg}$. crystalline egg albumin in solution, mixed with varying amounts of crude Merck lecithin, was injected into guinea pigs. These animals were tested nineteen days later for anaphylactic response to egg albumin. Results show that when the egg solution was mixed with lipoids, an increase in sensitivity resulted. In this case the lecithin presumably acts as an adsorbant. Other animals were injected with similar amounts of albumin precipitated with alum and mixed in like manner with varying amounts of lecithin. The effect of the lipoid in this case was quite opposite. Its presence in suitable proportions inhibited the development of sensitivity when the antigen was in particulate form.

This problem has also been investigated in another manner. Six day chick embryos have been shown by Dochez and Kneeland to be relatively non-antigenic. This observation has been confirmed by injecting guinea pigs with various amounts of whole embryo in saline suspension and shocking the animal nineteen days later with the same material-only slight reactions were noted. When, however, the embryos were extracted with alcohol, which removed most of the lipoids, the remaining material was highly antigenic. When the alcohol soluble portion was restored to the extracted fraction the mixture was relatively non-antigenic.

The Clinical Significance of Chorea as a Manifestation of Rheumatic Fever: a Study in Prognosis. By EDWARD F. BLAND (by invitation) and T. DucketT Jones, Boston, Mass.

An analysis of the prognostic significance of chorea as a manifestation of rheumatic fever has been made in 1000 rheumatic fever and chorea subjects. The results do not confirm the general impression that Sydenham's chorea is a grave manifestation of rheumatic fever.

Chorea occurred in 482 patients. Of these (over an average period of 8 years) 72 per cent exhibited other rheumatic fever manifestations, while 28 per cent had chorea alone.

The incidence of rheumatic heart disease in the above groups was:

$A$. Rheumatic fever (without chorea) 86 per cent.

$B$. Total chorea group 54 per cent.

Further analysis of this group $(B)$ :

1. Chorea with other manifestations of rheumatic fever, 73 per cent

2. Chorea without other manifestations of rheumatic fever, 3 per cent.
The severe manifestations of rheumatic fever (especially precordial pain, pericarditis, and congestive failure) occur twice as frequently in patients having rheumatic fever as in those having chorea in addition to rheumatic fever.

Over an 8 year period death occurred in only 0.7 per cent of the cases with chorea alone; in 14 per cent in the rheumatic fever and chorea group; and in 32 per cent of the straight rheumatic fever group.

Chorea is hence considered a mild manifestation of rheumatic fever and one not especially conducive to the development of rheumatic heart disease.

Studies in Streptococcal Immunity:-Erysipelas. By Wesley W. SPINK (by invitation) and Chester S. KeEFER, Boston, Mass.

As a part of an investigation of the response of the body to $\beta$-hemolytic streptococcal infection, patients with erysipelas have been studied. The investigation has been divided into two parts. 1. A survey of the various epidemiological, clinical features and course of the disease as it occurs in the Boston City Hospital. This included a review of 1400 cases with special reference to age and seasonal incidence, site of lesion, complications, mortality and factors influencing the outcome of the disease. 2. A small group of patients with erysipelas were studied to determine the time of the appearance of antibodies as measured by: (1) whole blood killing power; (2) anti-streptolysin; (3) anti-fibrinolysin; (4) complement; (5) agglutination reactions; (6) skin reactions.

It was found that the general mortality in the group of patients with erysipelas was 16.2 per cent and this was influenced by age and debilitating diseases. The death rate was highest in the 1st, 5th, 6th and 7th decades, whereas the morbidity was highest in the 3rd and 4th decades. The highest death rate occurred under one year of age, and the lowest in the second and third decades. With this information at hand, an attempt was made to determine the presence of antibodies in the circulating blood during the course of the disease. It was found that the whole blood killing power for the patient's own organism increased during and after the disease had subsided; there was also an increase in the anti-streptolysin titre of the blood serum and an increased resistance of fibrinolysis. There were no consistent fluctuations in the titre of the complement, but it was more common to observe a diminishing titre in the blood serum during the course of the disease and a return to the previous level following recovery. Agglutinins to the patient's own organism were not detected during or following recovery. The skin reactions to the streptococcal nucleoprotein showed a positive reaction in only 66 per cent of the cases.

From the observations so far it is possible to state that the recovery from erysipelas is associated with, and followed by, the development of antibodies to the infecting organism. There is, in addition, evidence that the presence of circulating antibodies will not prevent 
the development of recurrent attacks of erysipelas nor prevent the invasion of the blood stream from the local lesion. Further studies are being carried out to gain more information regarding the recovery process and the immune mechanism involved.

The Nature of the Secondary or " $T$ " Process of the Electrogram of Cardiac Muscle. By A. GARRARD MACLEOD, New York, N. Y.

The normal form of the secondary or " $T$ " process of the electrogram and the effect of local cooling on this process have been studied in the frog's auricle. The results obtained can be explained by a mathematical analysis similar in principle to that used by Wilson, Macleod and Barker in explaining the primary deflection of the electrogram of the dog's auricle. However, a simple graphical scheme has been devised which has been found to be much simpler and more convenient. From this analysis it appears that the velocity of spread of both the primary and secondary processes is the same, but that the potential differences which give rise to the secondary or " $\mathrm{T}$ " deflection are of opposite sign, smaller magnitude and much longer duration than those which give rise to the primary deflection. While it was found convenient to use the frog's auricle for most of the experiments upon which this work is based, it can be shown that the process is essentially the same in other varieties of cardiac muscle. It is believed, therefore, that it will be possible to substitute for the purely empirical interpretation of the " $T$ " deflection one which explains such changes as take place in it in terms of the velocity with which the process spreads and the magnitude and duration of the potential differences which develop in the muscle units.

Observations on the Components of Split First Heart Sounds. By Charles C. Wolferth and Alexander Margolies (by invitation), Philadelphia, $\mathrm{Pa}$.

We have recently presented evidence to indicate that when the first heart sound is split, there is asynchronism in ejection from the two ventricles. This finding may be regarded as supporting but not actually proving the postulate that one component of sound originates in each ventricle. In view of the fact that, as had been previously shown, the loudness of the first heart sound is greatly influenced by the As-Vs time relation, it seemed possible to test the validity of the postulate in cases exhibiting both split first sounds and varying As-Vs intervals. Long strips of simultaneously recorded sound tracing and electrocardiogram were made in two cases with complete heart block, and split first sounds. In both of these cases it was noted that during a certain range of As-Vs time intervals the two sound components varied independently of each other. The variation in each component depended on its own time relation to auricular contraction.

This behavior of the two sound components is in harmony with the postulate that one component is produced in each ventricle. As a matter of fact, the independent variations in the two components appear to exclude the possibility that both originate in the same ventricle.

Fragmentary observations in other cases with split first heart sounds and varying As-Vs intervals showed behavior similar to that of the two completely studied cases. Furthermore, in a case with a markedly prolonged, but not split, first sound the largest recorded vibrations occupied the first or second half of the first sound depending on the As-Vs time relation.

These observations support the view that the important duality of single as well as split first sounds consists of components contributed by the two ventricles.

The Quantitative Relationship Between the Amount of the "Intrinsic Factor of Castle" and the Maturation of Red Blood Cells in Patients with Pernicious Anemia. By S. M. GoldhaMer (by invitation), RAPHAEL IsaAcs and Cyrus C. Sturgis, Ann Arbor, Mich.

If the intrinsic factor of Castle is absent from the gastric juice of patients with pernicious anemia, there are two questions to be answered: (1) Why do any red blood cells mature in these patients? and (2) Why do these patients, in relapse, have different red blood cell levels? The secretion of gastric juice, with or without histamin injection, in 176 collections from 26 patients with pernicious anemia in relapse, was studied. The average secretion per hour in these patients was $20 \mathrm{cc}$. as compared with $150 \mathrm{cc}$. per hour in normal individuals under the same conditions. Gastric secretion collected from untreated patients with pernicious anemia was incubated with ground beef steak and then fed daily to two patients with pernicious anemia. A third pernicious anemia patient was given intramuscular injections of his own gastric juice. Data on the blood changes which followed are given. The response suggests that patients with pernicious anemia do secrete the precursor of the hematopoietic stimulant, but it is deficient in quantity. Further analysis reveals a direct relationship between the gastric juice volume and the red blood cell level in relapse, that is, the less the amount of gastric secretion, the lower the red blood cell count.

Hematopoietic Material from Liver Active in Pernicious Anemia. By H. D. DAKIN (by invitation) and R. WEST, New York, N. Y.

The preparation from commercial liver extract of products clinically active in causing remission in pernicious anemia is described. The method is based on the removal of much relatively inactive material by precipitation with alcoholic calcium acetate, followed by precipitation of the active material with Reinecke acid. The decomposition of the Reineckate requires special methods which are described. Subsequent purification is effected by "salting out" the active material with ammonium sulfate and later by the use of either magnesium sulfate or of flavianic acid. Thirty mgm. of the product caused a perceptible reticulocyte response in suitable pernicious anemia patients while $80 \mathrm{mgm}$. have given a maximal response. 
Under suitable conditions substantially the whole of the active material is precipitable by ammonium sulfate since none could be recovered from the filtrate. Precipitation in the magnesium sulfate is quantitatively less complete. The yield of purified product approximates 1 per cent of the dry liver extract.

The clinical activity of the products is readily abolished by exposure to cold $1 / 2 \mathrm{~N}$ sodium hydroxide and by boiling for 1 hour with $1 / 2 \mathrm{~N}$ sulfuric acid and also by salts of heavy metals. Exposure to alkali involves extensive racemization.

On hydrolysis of the active material the following products were obtained. (a) An aminohexose similar to glucosamine but not definitely identified as such. It gave phenylglucosazone on treatment with phenylhydrazine and pyrrol derivatives on condensation with acetylacetone and ammonia on treatment with alkali. Chondrosamine was absent. (b) The following amino acids were present in all preparations so far obtained: lysine, arginine, glycine, leucine, hydroxy, proline, aspartic acid. Crude preparations contained in addition histidine, glutamic acid, glycine and possibly traces of phenylalanine. No other carbohydrate or amino acid groupings were detected. The product, unlike glucosamine, gives a positive Molisch reaction, but we find that glucosamine peptides behave similarly. Pyrimidine or purine bases were absent. No claim to strict chemical individuality is advanced since the separation of aminohexose polypeptides must of necessity be extremely difficult.

\section{The Multiple Nature of the Pernicious Anemia Principle}

in Liver. By Cyrus H. FISKE (by invitation) and Y. SubBarow (by invitation), and Bernard M. JACOBSON, Boston, Mass.

A preliminary report of the response of the guinea pig's reticulocytes to materials which are effective in pernicious anemia was presented before this society last year. Since that time the indirect evidence that the guinea pig's response is related to substances which are concerned with human hematopoiesis has been strengthened by the fact that the liver of a second patient, dying in a relapse of pernicious anemia, has proven quantitatively almost completely inert in the guinea pig.

But in addition to the indirect evidence for the validity of the guinea pig phenomenon, more direct evidence has been obtained. During the past few years work has been in progress on the isolation from the liver of the therapeutically active substances. The successive liver fractions derived by chemical procedures have been tested on both guinea pigs and on patients. Both methods of testing yielded corresponding results, as long as a high degree of purification was not attained. But on further purification, fractions were obtained which were positive in the guinea pig, but which were devoid of therapeutic activity. To date there have been separated from liver at least three different fractions, of which two have been brought to a crystalline state. The separate guinea pig activities of each of the three fractions total about 95 per cent of the guinea pig activity of the crude liver extract used as a starting point in the separation. Each of the three fractions exhibits a quantitatively different degree of guinea pig activity, but each fraction, when separately administered by the intramuscular route to the patient suffering from pernicious anemia, is therapeutically completely inert. On the other hand, a mixture of the fractions is therapeutically highly active.

The above facts furnish, therefore, direct evidence for the biological validity of the guinea pig phenomenon and indicate that the therapeutic action of liver in pernicious anemia depends upon the combined effect of at least two substances.

The Relation of Fluctuations in the Number of Reticulocytes in the Guinea Pig to the Injection of Liver Extract. By Louis S. Goodman (by invitation), ArTHUR J. Geiger (by invitation) and Theodore G. KLUMPP, New Haven, Conn.

In the last proceedings of this Society, Jacobson described a "pernicious anemia-like state" in the guinea pig in which a specific reticulocytosis was induced in certain of the animals by the injection of potent liver extracts.

In attempting to utilize this phenomenon for the assay of liver extracts we found that when suitable animals with low reticulocyte counts were injected with potent extracts, a reticulocyte increase followed in $\mathbf{4 0}$ per cent of the experiments. However, the same response occurred in reactive animals after the injection of normal saline. Moreover spontaneous abrupt increases in the number of reticulocytes were so common that eventually the tenuous distinction between reactive and non-reactive animals was usually destroyed. It seemed highly probable that all the reactions were either non-specific or spontaneous in nature. A total of 141 tests on 69 guinea pigs was made.

On theoretical grounds there is no physiological basis for the development of a reticulocytosis after liver in guinea pigs with normal blood counts, any more than that such a phenomenon should occur in normal human beings or in pernicious anemia patients with normal blood counts. Moreover the spontaneous fluctuations in the number of reticulocytes in the normal guinea pig are of such a character that the use of this phenomenon for the bioassay of liver extracts is extremely hazardous.

Physiological "Macrocytic Anemia" of the Fetus. By M. M. Wintrobe and (by invitation) H. B. ShUMACKER, JR., Baltimore, Md.

It is well known that the red corpuscles of the newborn are larger than those of the normal adult. Little study has been made, however, of the size and number of the corpuscles in the fetus. Examination of the blood of feti of man, the pig, rabbit, rat, cat and dog, has revealed that macrocytosis is more marked and the red cell count is lower, the less mature the fetus. In comparison with the blood of the adult, there is found in the fetus what may be called "macrocytic anemia." As the fetus develops, the erythrocyte count rises and the size 
of the cells diminishes. The proportion of nucleated red corpuscles decreases rapidly, but the percentage of reticulocytes falls more slowly. In many respects, the blood of the mammalian fetus resembles that of cases of pernicious anemia which are being subjected to an effective, continuous and extremely potent stimulus. It seems plausible that this stimulation is afforded by a substance similar to, or identical with, the antianemic principle of Castle. Since, presumably, there is no gastric digestion in the fetus and no combination of "intrinsic" and "extrinsic" factors occurs, it is probable that the effective material passes from the stores of the mother to the fetus through the placental circulation. The biologic relationship of fetal hematopoiesis and that observed in pernicious anemia during liver therapy is being investigated.

The Effect of Irradiation on Platelet Production in Patients with Essential Thrombocytopenic Purpura Hemorrhagica. By Stacy R. MetTIER and (by invitation) Robert S. Stone, with the technical assistance of Katherine Purviance, San Francisco, Cal.

Six patients with essential thrombocytopenic purpura comprised a series for this study. Prior to treatment the platelets were about 10,000 per cu. $\mathrm{mm}$. in one patient and varied between this figure and 40,000 in the others. All patients received $x$-ray therapy over the spleen of $200 \mathrm{R}$ units, and in one patient who had a recurrence of symptoms $300 \mathrm{R}$ units were later used. The patients received a total of from 1260 to $3300 \mathrm{R}$ units. Four of these patients showed an increase in platelet production beginning within 24 hours and going up as high as from 250,000 to 400,000 per $\mathrm{cu}$. $\mathrm{mm}$. in 4 to 5 days. In one patient with chronic thrombocytopenia of two years duration no effect was shown following liver extract therapy, multiple transfusions, large doses of iron and ammonium citrate daily, high calcium diet, spleen marrow or Lextron; but a definite rise in platelets occurred following $x$-ray treatment. In one patient a high protein diet failed to increase platelet production, but there was a rise after $x$-ray treatment. In two patients no increase of platelets was produced by $x$-ray, ascorbic acid, anti-vennin, multiple transfusions or splenectomy, and the patients died as the result of hemorrhage.

The Haematology in Multiple Sclerosis. By PhILIP Solomon (by invitation), MARY E. DAILEY (by invitation) and TRACY J. PUtNaM, with the technical assistance of Ruth G. Coughlan, Boston, Mass.

Various features of the blood have been studied in patients with multiple sclerosis. It has been shown that the blood clotting time decreases following such stimuli as subcutaneous adrenalin or intravenous typhoid vaccine, and that the decrease is more marked and more prolonged in patients with multiple sclerosis than in control patients. Further studies have been made in the endeavor to throw light on this increased lability of the blood clotting time. The following chemical determinations were made and found to be normal: sodium, chloride, calcium, phos- phorus, fluorin, nonprotein nitrogen, total protein, albumin, globulin, albumin-globulin ratio, total solids and sugar. Analyses of the arterial and venous blood oxygen and carbon dioxide content were also within normal limits. The blood fibrin content was found to be high in a large proportion of the patients with multiple sclerosis. The blood platelets were frequently found to be increased in these patients. Prothrombin determinations were within normal limits. Brickner's experiments on blood lipase were repeated, and the results found to be inconclusive.

The abnormal gold sol curve in the spinal fluid of multiple sclerosis was shown to be due to the globulin contained therein. Since the blood globulin is not increased in multiple sclerosis, a qualitative study of the globulin is in progress. It has already been shown that solutions of blood globulin from patients with multiple sclerosis produce "paretic" gold sol curves, as compared to moderate "mid-zone" curves obtained from solutions of globulin from control patients.

These findings lend support to the hypothesis that multiple sclerosis is a disease due to multiple small venous thrombi in the central nervous system.

Nutritional Deficiency and Water Retention in the Toxemias of Pregnancy. By Maurice B. Strauss, Boston, Mass.

Water retention is generally recognized as a common concomitant of true toxemia of pregnancy and probably occurs to a certain extent in normal pregnancy. Three of the many factors involved in water retention in the non-pregnant individual, the oncotic pressure of the plasma proteins, the venous pressure, and the nutritional state, have been investigated in pregnancy.

The average oncotic pressure of the plasma proteins in 10 patients with eclampsia was $175 \mathrm{~mm}$. of water; in 20 patients with non-convulsive toxemia of pregnancy, $215 \mathrm{~mm}$.; in 15 normal pregnant women who had partaken of low protein diets $232 \mathrm{~mm}$; and in 20 normal pregnant women who had eaten 60 to 100 grams of protein daily, $258 \mathrm{~mm}$.

The average venous pressure of 20 normal pregnant women was $10 \mathrm{~cm}$. of water and of 20 women with nonconvulsive toxemia of pregnancy $13.3 \mathrm{~cm}$. of water, a statistically insignificant difference. The average venous pressure of both groups, however, was at least double that of normal non-pregnant subjects.

Dietary histories of the 20 women with non-convulsive toxemia revealed low protein intakes, frequently over a period of years. Gastro-intestinal disturbances were common. Fifteen of these women were given a diet consisting of $260 \mathrm{gms}$. of protein, $150 \mathrm{gms}$. of carbohydrate and 70 grams of fat. This included 300 grams of raw liver pulp daily. Ten of the women received daily intramuscular injections of vitamin $B_{1}$ concentrate and of liver extract of the type commonly employed in the treatment of pernicious anemia. This material is believed to contain fractions of the vitamin B complex not present in the $B_{1}$ concentrate. These injections were given be- 
cause of a possible relationship between a deficiency of vitamin $B$ and water retention such as may occur in beriberi. Edema disappeared and weight was lost uniformly by these 15 patients. In no case did the arterial blood pressure rise, nor was there any fetal mortality after the institution of this treatment. Headache and visual disturbances abated. Albuminuria did not increase. The non-protein nitrogen of the blood did not rise above 35 mgm. per $100 \mathrm{cc}$. The oncotic pressure of the plasma proteins rose an average of 7 per cent.

Five of the 20 women with non-convulsive toxemia of pregnancy were given a diet containing 20 grams of protein, 400 grams of carbohydrate and 65 grams of fat. Two patients improved, the arterial blood pressure falling to within normal limits, one patient's condition was unchanged, and two showed increasing albuminuria and a further elevation in the arterial blood pressure. Weight changes were not significant. The oncotic pressure of the plasma proteins fell an average of 9 per cent.

These observations suggest that water retention occurs in certain cases of toxemia of pregnancy as a result, among other factors, of a decreased oncotic pressure of the plasma proteins, and that this may probably be relieved or prevented in many instances by the administration of a diet rich in protein and containing all other nutritional factors.

Studies on the Urinary Proteins Found in Cases of Socalled Orthostatic Albuminuria. By Lay Martin, Baltimore, Md.

In the urine of patients diagnosed as having orthostatic albuminuria and in that of one having albuminuria of years duration, it has been found that the protein present is not albumin. It falls within the class of globulins or gluco-proteins, since a carbohydrate radical is constantly in association with it. It has been isolated in a sufficiently pure form for the determination of components; the iso-electric point has been determined, and it has been crystallized. Qualitative studies have been carried out on the so-called acetic acid body often found in the urine of these cases. This also has protein characteristics and is intimately associated with the carbohydrate radical. Full case records of all patients are on hand.

Experimental Agranulocytosis. By W. B. Chew (by invitation), John S. Lawrence, and D. J. Stephens (by invitation), Rochester, N. Y.

A leucotoxic serum was produced by immunizing rabbits intravenously with a suspension of guinea pig leucocytes containing seventy-five to ninety per cent amphophiles. Hemolysins were absorbed from the anti-serum with guinea pig red blood cells.

Four guinea pigs were given intracardial injections of this anti-serum. The amphophiles disappeared from the blood within five minutes.

Fifty guinea pigs were given a single intraperitoneal injection of this anti-serum. The amphophiles disappeared within one to seven hours and began to reaccumulate in thirty to forty-eight hours. Their reappearance was not preceded by the appearance of myelocytes or stab forms.

Four guinea pigs received repeated intraperitoneal injections at various intervals in doses from $0.5 \mathrm{cc}$. to 2.0 cc. Observations upon these animals demonstrated that successive injections of the same amount of anti-serum had less and less effect. When the dose of anti-serum was increased the original effect was obtained. This tolerance could not be removed by administering a desensitizing dose of normal rabbit serum.

Two animals received daily intraperitoneal injections in gradually increasing amounts. This prolonged the absence of amphophiles to four days, after which they appeared in increasing numbers in spite of continued injections.

In all animals the number of lymphocytes in the blood was somewhat decreased during the period of maximum effect of the anti-serum. The monocytes, eosinophiles, and basophiles behaved as they do after injections of normal rabbit serum. The number of red blood cells and platelets and the body weight were not significantly affected.

The amphophiles which had disappeared from the blood could not be found in the tissues of animals sacrificed immediately after their disappearance.

Differential cell counts on the bone marrow of injected animals disclosed almost complete absence of adult amphophiles and a decreased percentage of myelocytes at the end of twenty-four hours. Observations on the bone marrow of repeatedly injected animals disclosed a marked myeloid hyperplasia with a percentage of adult amphophiles which corresponded to the effectiveness with which anti-serum was controlling the number of amphophiles in the peripheral blood.

Microscopic examination of the tissues of injected animals revealed lymphoid and endothelial hyperplasia in the spleen and lymph nodes. There was no definite morphological evidence of damage to other body cells.

The Cellular Constituents of Normal Human Synovial Fluid with a Consideration of Influencing Factors. By Charles F. Warren (by invitation), Granville A. BennetT (by invitation) and Walter Bauer, Boston, Mass.

Cytologic examinations have been made on 150 synovial fluids obtained from human knee joints immediately after death from individuals who had had no joint symptoms. Wide variations in the number of nucleated cells and in the percentage of individual cell types were observed. This and additional data are presented in an attempt to establish what variations in the total number of nucleated cells and individual cell type percentages can occur and still be within the limits of so-called normal.

Thus it has been shown:

1. That postmortem intra-articular cellular migration may take place but is not associated with significant variations in cell percentages or any increase in polymorphonuclear leucocytes.

2. That an increase in the number of circulating leuco- 
cytes or a marked polymorphonuclear leucocytosis can occur without any reflection of such variations in the synovial fluid cytology.

3. That the increased number of nucleated cells and percentage of phagocytic cells observed in certain instances is best explained by the increased amount of debris resulting from the cartilage defects present.

4. That an increase in the total amount of synovial fluid, as occurs in oedematous patients, results in a reduction of the total number of nucleated cells per cubic millimeter.

5. That high total cell counts and high polymorphonuclear leucocyte percentages are observed in the synovial fluids obtained from patients dying with any type of severe infection.

Thus, by selecting the synovial fluids obtained from patients who had neither oedema nor infection, one is able to construct a table showing the minimal, maximal and average number of nucleated cells as well as individual cell percentages contained in normal synovial fluid. The variations which still occur are best explained as being due to the degree of wear and tear, minor traumata or irritants, to any one of which all joints must be subjected from time to time.

Knowing the cytological variations which can occur in normal synovial fluid and synovial fluid obtained from patients with severe infections, we shall be better able to evaluate the cytological variations we have observed in joint effusions in the various arthritides. Whether this information will allow for a better interpretation of the joint aches and pains so often complained of in individuals with acute infections will depend upon whether or not studies now in progress will show that synovial membrane changes are regularly associated with variations in the synovial fluid cytology.

\section{READ BY TITLE}

The Seat of the Disturbance of Carbohydrate Metabolism in Hyperthyroidism. By T. L. Althausen and (by invitation) G. E. Wever, San Francisco, Cal.

A review of available data on the respiratory quotient, arteriovenous blood sugar difference and behavior of inorganic phosphates of the blood in hyperthyroidism indicates increased utilization of sugar by the tissues. This speaks against pancreatic insufficiency as the cause of reduced dextrose tolerance in hyperthyroidism, because diabetes mellitus is characterized by reduced utilization of sugar.

After ingestion of $\mathbf{4 0}$ grams of galactose, the dextrose and galactose fractions of the blood were followed in normal individuals, in patients with hyperthyroidism, with diabetes, and with hepatic diseases.

Results: 1. A greater than normal increment of dextrose occurred after 5 minutes in patients with hyperthyroidism and with diseases of the liver, while patients with diabetes responded normally. 2. Tolerance to galactose was consistently reduced in hyperthyroidism and in hepatic disease, whereas in diabetes it was normal.

.Thyroidectomy corrected the abnormalities observed after ingestion of galactose. Psychic factors were ruled out by control experiments with saccharin.

Conclusions: Our findings point to the liver as the chief seat of the disturbance of carbohydrate metabolism in hyperthyroidism. This is confirmed by liver function studies and pathological data. Dextrose therapy, especially as a preoperative measure, is indicated on this basis and is supported by favorable clinical evidence.

Group Examinations for Pulmonary Tuberculosis. By Robert G. BLOCH and (by invitation) BYron F. Francis and Grace Hiller, Chicago, Ill.

The absence of symptoms does not indicate the absence of pulmonary disease; physical examination is not adequate in ruling it out. The gradual recognition of these facts has led to roentgenological group examinations in increasing numbers. The superiority of such examinations as against group testing methods with tuberculin is discussed.

Four thousand adults, students and employees, were examined by fluoroscopy or chest films at the University of Chicago. The definite classification of findings as to the activity of diagnosed lesions demands a period of at least six months. A detailed classification comprising the medical aspects of the management of patients has been worked out. The percentage of active tuberculosis in our group was 1.2 per cent. Observations were made on the occurrence of healed (calcified) pulmonary tuberculous lesions (Ghon's tubercles). The incidence of such lesions was found to be considerably less in the younger individuals than in the older ones. This observation, which should be verified in a larger group tends to throw a new light on the significance of calcifications as to infection and reinfection with tuberculosis. The possibility that many of the calcified small lesions are due to adult reinfection seems great.

The group examinations were extended to those who had been in close contact with the individuals found to have active tuberculosis. This procedure was initiated on the basis of our experience that the great majority of cases of adult tuberculosis are due to a massive, exogenous superinfection, rather than to a revival of lesions acquired during childhood.

Roentgenological group examinations of the general population, chiefly of industrial and other special groups, are recommended.

The Familial Nature of Blood Pressure Reactions as Studied by a Standard Stimulus (Cold). By George E. Brown and (by invitation) Edgar A. Hines, JR., Rochester, Minn.

A constant abnormality found in all cases of essential hypertension has been an excessive response of the blood pressure to stimulation. A standard test, using a simple type of stimulus (ice water at $5^{\circ}$ C.), has been evolved for measuring this response. This test, when applied to a large number of normal subjects, those suffering from various types of disease, and those having essential hypertension, shows that there are two types of reactors: 
hypo-reactors, or " normal reactors," and hyper-reactors. Members of families of two, three and four generations have been tested by this method, and the familial or constitutional nature of this characteristic over-response is demonstrated in a remarkable degree. Likewise, the constitutional nature of the hypo- or "normal" reaction shows similar familial characteristics.

A Study of the Mechanism of Circulatory Insufficiency in Sclerodactylia. By MYron Prinzmetal (introduced by W. B. Castle), Boston, Mass.

Raynaud's disease associated with sclerodactylia is more severe clinically, presents a more difficult therapeutic problem and has different experimental vascular reactions than Raynaud's disease without sclerodactylia. We propose that the tight skin in sclerodactylia has a constricting effect on the circulation of the fingers and thereby is an important factor in explaining these differences between Raynaud's disease with normal skin and Raynaud's disease with sclerodactylia.

In sclerodactylia the areas of greatest circulatory deficiency, as determined by skin temperature, occur where the pressure from the skin is greatest. If the skin is relaxed, a definite rise in temperature takes place which disappears when the skin is taut. In 3 cases in which unilateral sympathectomy was performed, no substantial increase in skin temperature occurred, since the tight skin prevented the denervated vessels from opening.

If a tight binding (finger of a small rubber glove) of about the same intensity as the tight skin in sclerodactylia is placed on a normal digit, the abnormal vascular reactions obtained by Lewis may be duplicated. We found by this method that the skin assumes and follows room temperature, does not have the vasodilator reaction upon exposure to cold and has smaller plethysmographic oscillations. Vasodilator impulses induced by the Landis test cause slight or no increase in skin temperature.

In sclerodactylia or in an experimentally bound normal finger, intermittent suction causes an increase in skin temperature, even though sympathectomy has failed to increase the flow. The mechanism of improvement is probably due to relaxation of the tight skin.

Cerebral Circulation: Constriction of Pial Vessels in the Unanesthetized Cat Produced by Stimulation of the Cervical Sympathetic Chain. By Caroline BedELI. Thomas (by invitation) and Stanley CobB, Boston, Mass.

1. A method is described whereby it is possible to study changes in calibre of the pial vessels in unanesthetized cats.

2. Stimulation of the cervical sympathetic chain in unanesthetized cats was followed by slight constriction of the ipsilateral pial arterioles (average 6.7 per cent).

3. The constriction observed in unanesthetized cats was of the same order of magnitude and in no case greater than that reported in anesthetized cats.

The results obtained in this small series so closely re- semble those reported by Forbes and Wolff in anesthetized cats that it seems unlikely that anesthesia of the types they used lessens constriction of the pial arteries.

Experimental Bundle-Branch-Block in the Rhesus Monkey. By J. Hamilton Crawford, and (by invitation) George H. Roberts and David I. Abramson, Brooklyn, N. Y.

Uncertainty concerning the electrocardiogram in bundlebranch-block is related to experimental work of Lewis. A basic experiment in the formation of his view was transection of the right branch in a monkey. The report contained a chart representing the chief initial deflections directed upward in Lead I and downward in Lead III. It seemed important to repeat this experiment.

Twelve monkeys were used. After control electrocardiograms the branch was cut. Four experiments were completely successful. The others were discarded because of even minimal damage to the opposite septal wall. In no instance were curves obtained inconsistent with those described. The left branch was divided twice. In one, subsequent histological examination showed complete division with the right intact. Characteristic curves were obtained, the chief initial deflections being upward in Lead I and downward in Lead III. Ventricular extrasystoles, after stimulating the opposite ventricle, were identical. The right division was cut twice also. In one, discordant curves were obtained with the chief initial deflections downward in Lead I and upward in Lead III. The second showed concordant curves with the main deflections downward in all leads. These curves support the more recent interpretation, opposite to the earlier view:

Parathyroid Autotransplantation in the Dog: Evaluation of Halsted's Law of Deficiency. By Pнilip SнamBAUGH (by invitation) and ElliotT C. Cutler, Boston, Mass.

A series of parathyroid transplantation experiments in dogs was undertaken to test the validity of the "law of deficiency" which was proposed by Halsted some twentyfive years ago and which has been widely accepted since that time. Halsted concluded, as a result of experimental studies, that the autotransplant would not survive unless a parathyroid deficiency of more than fifty per cent had been created. He also found that parathyroid tissue transplants in excess of what was urgently required by the organism did not survive.

In our experiments the parathyroid deficiency at the time of transplantation was varied from twenty-five to one hundred per cent. After varying intervals the grafts were excised and examined microscopically. Although there were a certain number of failures in each group. we found that the graft survived and in many instances retained its original size and structure for periods up to three months in experiments where the parathyroid deficiency was only twenty-five or fifty per cent as well as in experiments where it was seventy-five or one hundred per cent. Moreover, we found that two separate 
autografts placed at the same time in animals with a parathyroid deficiency of only fifty per cent would both survive for periods up to two months.

Our observations lead us to believe that a pre-existing deficiency or a physiological need of the organism for the tissue in question is not a requirement for the immediate survival of parathyroid autografts. We have not concerned ourselves in this study with the problem of the factors involved in the ultimate survival of such transplants.

The Aetiology of Agramulocytosis with Particular Reference to the Factor of Drugs. By William DameSHEK, Boston, Mass.

The importance of the factor of drugs in the development of agranulocytosis was studied (1) by examination of clinical records in typical cases, (2) by administration of certain drugs such as amidopyrine to recovered patients, and (3) by the administration of amidopyrine and "allonal" to "normal" subjects. Clinical and hematological effects were noted and the question of allergic sensitivity was investigated.

The following facts were established: (1) that various drugs were definitely linked with the development of agranulocytosis; (2) that certain patients showed extreme hypersensitivity (not allergy) to amidopyrine with the reproduction of granulocytopenia; (3) that most (63 per cent) of " normal" subjects developed definite leukopenia and granulocytopenia after administration of amidopyrine or "allonal." The hourly leukocyte counts were greatly disturbed. Upon discontinuance of the drug in these cases striking leukocytosis ("release phenomenon") frequently occurred.

The following conclusions are at present justified:(1) although multiple aetiological factors are undoubtedly operative in many cases of agranulocytosis, the most important one appears to be that of drugs; (2) the exact mechanism of this action is unknown, although an unusual hypersensitivity probably not allergic is apparent; (3) this hypersensitivity appears to affect the normal maturation and release of cells in the bone-marrow with resultant granulotytopenia.

The Control of the Hypothyroid State After Total Thyroidectomy in the Treatment of Chronic Heart Disease. By David Davis and Herrman L. Blumgart, Boston, Mass.

Approximately seventy-five patients in this clinic on whom total thyroidectomy has been performed for the treatment of heart disease have been kept free from unpleasant symptoms of myxedema at basal metabolic rates approximating minus 30 per cent by the administration of small doses of thyroid. In the majority of cases thyroid medication was required by the end of the third postoperative month, some weeks after the basal metabolic rate had reached its lowest level.

To accomplish the two-fold purpose of maintaining a low basal metabolic rate, with its coincident low basal cardiac work and at the same time not allowing the patient to suffer from myxedema symptoms (puffiness of face, excessive fatigue, drowsiness, emotional instability, etc.), an appropriate thyroid dosage varying from $1 / 20$ to 1 grain daily, usually $1 / 8$ to $1 / 4$, was worked out in each case by trial and error. Patients were seen at frequent intervals and also instructed to return to the clinic if any unpleasant symptoms developed. Nervous irritableness, unaccompanied by other untoward symptoms, occurred in a few patients and required immediate thyroid therapy.

Symptoms frequently became less marked during the postoperative course, so that thyroid dosage could be subsequently decreased and in some instances omitted. In practically every patient the untoward symptoms were controlled by properly regulated dosage, the metabolic rate being maintained at approximately minus 30 per cent. The small doses of thyroid necessary did not greatly increase the work of the heart and, therefore, generally did not interfere with the clinical improvement following total thyroidectomy.

Observations on Coronary Blood Flow in Aortic Stenosis and Aortic Regurgitation. By JAY C. Davis, Minneapolis, Minn.

A heart-lung preparation was used for the study of coronary blood flow. Aortic stenosis and aortic regurgitation were made in such a manner that the valve was not damaged. The blood flow through the canulated circumflex coronary artery was studied with perfusion from the aorta at pulsatile pressures and from a perfusion botthe at a pressure below, equal to, and above aortic pressures. The coronary flow per minute was measured by means of a stromuhr. With this method the coronary flow per minute in the same heart with a normal aortic valve, with aortic stenosis, with aortic regurgitation and again with a normal valve was measured.

It was found that a diminution in coronary flow occurs in both aortic stenosis and aortic regurgitation independent of the drop in diastolic pressure. This was evident for the decrease in coronary flow occurred in the valve lesions when the circumflex artery was perfused from the pressure bottle set at such a height that the perfusion pressure was 10 to $20 \mathrm{~mm}$. mercury higher than the systolic pressure in the aorta. Furthermore, similar results were obtained using the whole animal.

The explanation of these results requires additional study. To determine the effect of a single cardiac cycle on the coronary flow in aortic valve lesions, experiments now are being conducted by means of a hot wire anemometer.

The Influence of Auricular Fibrillation on the Course of Rheumatic Heart Disease. By Arthur C. DeGraff and (by invitation) CLAIRE LingG, New York, N. Y.

This paper is the third in the series describing the events in the course of rheumatic heart disease. The records of 644 patients followed to death are used. The first of two studies now in press describes the factors pertaining to age at initial infection, duration of life 
and cause of death. The second study describes the influence of valvular lesions on the course of rheumatic heart disease. In this paper the influence of auricular fibrillation on the course of rheumatic heart disease is discussed.

Of the 644 cases, 276 developed auricular fibrillation before death. The others, as far as we could determine, died while still having a sinus rhythm. It was possible, therefore, to compare the length of life in these two groups. The following facts were elicited:

No significant difference was noted in relation to sex. The highest incidence was found among cases with mitral stenosis.

The longer the duration of rheumatic heart disease, the greater the incidence of auricular fibrillation.

In a number of ways it is demonstrated that auricular fibrillation is usually a late manifestation in heart disease and that it is only observed in relatively long standing cases.

Once auricular fibrillation appears, however, the duration of life is rarely longer, on the average, than $21 / 2$ years from the onset of auricular fibrillation.

The Clinical Standardization of Digitalis. By F. R. Dieuaide and (by invitation) C. L. Tung and C. W. BIEN, Peiping, China.

In an attempt to achieve quantitative results in the standardization of digitalis in man it was decided to rely chiefly, and in the end entirely, on objective observations capable of measurement. Clinical congestive failure introduces many uncontrollable variables; it was, therefore, eliminated from consideration. The samples of digitalis to be tested were given at suitable intervals to the same subjects under conditions as closely similar as possible. To test the possibility of separating different potencies of the drug the same doses of three strengths of a standard preparation (related as $75: 100: 125$ ) were given. (So far as is known the capacity of methods for clinical standardization has not been so tested before.) The samples were supplied as "unknowns," A, B, and C, by the Department of Pharmacology, and only after our conclusions were reached were further data available. The observations included symptoms, blood pressure and electrocardiographic measurements. Among them only the length of the " $Q-T$ " interval in relation to the length of the cardiac cycle seemed to offer the possibility of quantitative separation of the samples of digitalis. Through the changes in this factor it was possible to place the samples in their correct order of strength. A similar trial was made of two unknown samples of different leaves which had been extensively standardized in the laboratory. The results were compatible with the data supplied after the clinical trial. The study leads to the belief that clinical standardization cannot at present differentiate satisfactorily between digitalis preparations differing by much less than 25 per cent and to the position that close calculation of digitalis dosage is not necessary. The difficulties of clinical standardization are considered and a standard plan is drawn up.
The Effect of Severe Anemia on the Heart and Circulation. By Laurence B. Ellis, Boston, Mass.

Cardiac failure and severe anemia frequently resemble each other in many respects in their symptomatology and physical findings. A study has therefore been made to determine the effects of severe anemia on the cardiovascular system. Forty-four patients were studied, and 26 of these were also examined when their anemia had improved. Thirty-three had dyspnea on exertion which disappeared in every case followed. Twenty showed dependent edema, and in all but 2 of the 10 followed it disappeared. One had typical anginal pain which ceased with relief of anemia. Twenty-eight patients had basal or apical systolic murmurs of varying intensity, and of the 21 followed these decreased or became absent in 11 . One patient also showed a diastolic murmur which disappeared. Twelve of the 23 cases who were followed by serial teleoroentgenograms showed a diminution in the cardiac size as the anemia lessened. In 6 the blood pressure increased definitely. Electrocardiograms were taken in every case and in 26 patients they were repeated following recovery. No serious abnormalities were present. In 5 there was an increase in the amplitude of the $\mathbb{T}$ waves and in 3 an increase in the amplitude of all complexes.

Severe anemia produces demonstrable changes in the heart and circulation, and these changes usually disappear with recovery from the anemia. Although some of the symptoms and signs which occur in severe anemia are similar to those occurring in heart disease and failure, there are certain manifestations of heart failure which are rarely if ever produced by anemia alone. These differential diagnostic signs are orthopnea, pulmonary or peripheral venous congestion, abnormal cardiac rhythms and marked electrocardiographic abnormalities.

The Influence of Inorganic Salts on Salyrgan Diuresis. By Marshall N. Fulton and (by invitation) Clayton B. Ethridge and DAN W. Myers, Boston, Mass.

Studies have been made on normal dogs to determine the modifying effect of various inorganic salts on salyrgan diuretic action. To establish an approximately similar state of water and salt balance, the animals were maintained for one week prior to each test day on a constant food, sodium chloride and fluid intake. On the test days normal equivalent amounts of different salts were administered as a single dose per os, followed in two hours by an intravenous injection of salyrgan. Quantitative measurements of urine output and analyses for changes in blood and urine chlorides and plasma $\mathrm{CO}_{2}$ combining power were made in each experiment. Control studies include comparable data on the action of salyrgan and of the various salts when given separately.

The results establish that acidifying salts plus salyrgan produce marked diuresis, whereas alkalinizing salts inhibit diuretic action. Neutral salts influence the diuretic action of salyrgan in the same manner as does water: a diuresis of moderate degree results. Acidifying salts working with salyrgan appear to show a syner- 
gistic rather than a summative diuretic action of the two substances. The extent of diuresis from salyrgan following an inorganic salt seems to be influenced chiefly by the resultant alteration of acid-base equilibrium rather than the availability of particular ions for excretion.

\section{Observations on the Sulphur Content of Urinary Protein.}

By G. P. Grabfield, Boston, Mass.

The constitution of urinary protein was studied in various types of proteinuria. The method consisted in analyzing the urine for total nitrogen and total sulphur before and after the precipitation of the protein by heat and 0.5 per cent acetic acid. The differences between these two sets of analyses represent the nitrogen and sulphur in the urinary protein. That the figures so obtained are valid analyses of the protein has been checked by analyses of the protein obtained in relatively pure form by dialysis.

We shall go no further than to compare the relation of nitrogen to sulphur in the protein excreted in various types of proteinuria. The only significant variation was found in patients showing the nephrosis syndrome. In such patients the protein excreted is very low in sulphur. The N/S ratio of such protein is often as $200: 1$ as compared with about 20:1 in other types of albuminuria. There is considerable daily variation in the sulphur content of excreted protein. This fits in with the observations of K. Lang and E. G. Schenck who observed daily and even hourly variations in the amino-acid construction of the plasma proteins.

Other types of albuminuria studied were those of chronic glomerulonephritis, toxemia of pregnancy, orthostatic, exercise and cardiac decompensation. In addition, there were single cases of mercuric chloride poisoning and hyperglobulinemia.

The findings here reported suggest a fundamental alteration in the protein metabolism affecting the structure of protein in nephrosis. Similar studies on protein structure in other conditions might prove fruitful.

The Frequency and Significance of Changes of the Expiratory Volume of the Chest during Routine Measurement of Basal Oxygen Consumption. By JAs. A. GREENE, with technical assistance of MURIEL WARD, Iowa City, Iowa.

Many of the technical errors that may occur during the measurement of the basal oxygen consumption by the closed circuit method have been pointed out, but the effects of changes of the expiratory volume of the chest have not been generally appreciated. Benedict found that this factor was not significant in normal subjects, but in patients Greene and Coggeshall observed changes which materially altered the calculated results.

Significant changes of the expiratory volume of the chest were found to occur in 23.1 per cent of 2985 spirograms obtained during routine measurement of basal oxygen consumption, introducing an error ranging from 15 to as much as 45 per cent. This error may result in under-estimation as well as over-estimation of the actual oxygen consumption. We shall discuss the conditions under which this error occurs and suggest a method of eliminating it.

The Effects of the Introduction of Substances into the Cisterna Magna on the Blood Pressure of Dogs. By H. Resnik, C. Pilcher and F. M. Mason (by invitation) and T. R. HARrison, Nashville, Tenn.

It is not yet known whether the several types of clinical hypertension are of nervous or of chemical origin. Most studies of pressor substances have been concerned with their action when administered intravenously or subcutaneously. Under such circumstances it is often difficult to distinguish between central and peripheral effects. In order to avoid this disadvantage, we have injected compounds into the cisterna magna and observed the blood pressure.

Various substances such as alkaloids, endocrine preparations, anaesthetics, other organic compounds and inorganic salts have been tested. Striking and prolonged pressor reactions have been observed from potassium and ammonium salts. When the cisterna is opened and the injection made caudad, effects are absent. Small amounts of these salts applied to the floor of the fourth ventricle cause a pronounced rise in blood pressure. Attempts to determine more exactly the site of action are in progress.

The pressor effects of potassium can be prevented by the previous administration of calcium. The injection of anions such as oxalate, phosphate and citrate, which diminish the ionization of calcium, results in prolonged rise in blood pressure.

Judging from the few cases so far studied, patients with uremia and phosphate retention have a diminution in the amount of ionized calcium in the spinal fluid, although the total calcium may be normal. The intracisternal administration of calcium salts has seemed to be beneficial in several patients with uremia.

\section{Hemoglobin Regeneration and Critical Changes in the} Plasma Proteins. By ClaRK W. Heath and (by invitation) F. H. L. TAYLOR, Boston, Mass.

Patients with severe anemia, who are regenerating blood, frequently show pitting edema and retention of fluids, unrelated to kidney dysfunction. A study of this phenomenon was made on the hypothesis that, since the red blood cells are rich in protein as compared to the blood plasma, the manufacture of red blood cells in the absence of any excess of protein in the diet may result in a reduction of the plasma proteins, thereby lowering the osmotic pressure of the blood.

The plasma proteins during blood regeneration were frequently reduced, even in the presence of a positive nitrogen balance. Edema appeared, however, only infrequently when the plasma proteins reached critical low levels. There was a great retention of nitrogen: the urine nitrogen was as low as 2 grams per day in some cases. Nevertheless, even in cases in which the nitrogen balance was negative, blood regeneration and a gain of total circulating nitrogen took place. 
It was concluded that a reduction of the plasma osmotic pressure is a factor in the production of edema observed in anemia undergoing remission. The observations emphasize the increased protein requirements of the patient recovering from anemia.

$V$ isualization of Congenital Arteriovenous Fistulas of the Extremities by Arteriography. By BAYARD T. HORTON and (by invitation) RALPH K. GHORMLEY, Rochester, Minn.

By means of arteriography with thorotrast the location and architecture of congenital arteriovenous fistulas of the extremities have been visualized and confirmed at surgical exploration. In the literature, prior to the use of arteriography, exploratory operations in attempts to close the fistulas had been followed by amputation of the involved extremity in 58 per cent of cases. Since the use of arteriography, where explorations have been carried out, amputation of the involved extremity in our experience has not been necessary in a single instance. Serial arteriograms illustrate the manner in which arteriovenous fistulas function. One can only interpret these properly when the pathologic physiology of a fistula is understood. The injected medium, like the blood, takes the course of least resistance, which is from the artery through the fistula to the veins. When the brachial or femoral artery is closed by pressure proximal to the point of injection of the thorotrast, there is always a leakage of the medium into the veins, which is invariably present when the first film is exposed. This is diagnostic of an arteriovenous fistula. The amount of filling on the venous side is proportional to the size of the fistula. If the fistula is large, the opaque medium will pass directly from the artery to the vein with little or no filling of the arterial tree distal to the site of the fistula. If the fistula is small, only a small amount of the opaque medium leaks into the veins. Enough remains in the arterial tree to visualize it completely distal to the site of the fistula. Detailed clinical and physiologic studies have been carried out in forty-one cases.

Blood Velocity at Varying Levels of Metabolism in Subjects With or Without Thyroid Disease. By J. W. Macy (by invitation), T. S. ClaIBorne (by invitation) and L. M. Hurxthal, Boston, Mass.

This study was begun to compare the blood velocity in patients with low metabolic rates without myxedema with the blood velocity in patients with myxedema. The study was then extended to include the following; normal individuals, patients with hypometabolism, myxedema, toxic goitre, toxic goitre with heart failure and heart failure without goitre. Over 120 subjects were tested by the decholin method.

The results show that low metabolic rates without myxedema give normal blood velocity rates. Some of these cases were due to proved pituitary deficiency, while in others the cause of the low B.M.R. was not determined. In myxedema, on the other hand, it was decreased. As would be expected increased blood velocity rates were found in toxic goitre, but in patients with congestive heart failure and toxic goitre normal values were obtained. In patients with congestive heart failure without thyroid disease decreased rates were found. The normal values found in toxic goitre with heart failure were interpreted as being due to counteracting effects of hyperthyroidism on the one hand and heart failure on the other.

The results in the cases of low metabolism without myxedema are additional evidence that myxedema is not synonymous with hypometabolism and thyroid atrophy secondary to deficient thyrotropic hormone of the pituitary, a theory quite in vogue at present.

Observations on the Character of the Pain Producing Substance in Contracting Skeletal Muscle. By L. N. KATZ and (by invitation) E. LINDNER and H. LANDT, Chicago, Ill.

The following procedures were found to lessen the amount of exercise necessary to cause continuous pain in contracting muscles of normal subjects: (a) generalized anoxemia, $(b)$ elevation of the $\mathrm{CO}_{2}$ content in the blood contained in an ischemic limb, (c) trapping the blood coming from the exercised lower extremities in an ischemic limb. Alkalinization of the subject with large quantities of sodium bicarbonate definitely increases the amount of exercise required to produce pain.

The stimulus for pain, from these observations, appears to be the accumulation of a chemical metabolic substance (or substances) which diffuses readily into the blood stream and is altered quickly when the oxygen supply is adequate. It appears to be an acid, such as lactic or phosphoric acid, formed during the catabolism of muscular activity.

\section{Study of Total and Basal Metabolism in Obesity and \\ Undermutrition. By J. LERMAN and (by invitation) \\ P. C. BAIRd, Boston, Mass.}

The total metabolism of 6 underweight and 8 overweight patients was studied by determining their " insensible perspiration" according to the method of Benedict and Root and of Newburgh, slightly modified. The basal metabolism was studied simultaneously. Several of the patients were observed over long periods of time while undergoing changes in weight, i.e. gain in weight in the underweight group and loss of weight in the obese group.

A correspondence between the insensible weight loss at night and the basal metabolic rate, as observed by Benedict, was found also in 9 of our cases, but was doubtful in 2 and absent in 3.

There are two types of individuals represented in the undernutrition group:

Type 1: The total metabolism (insensible perspiration) in this type is low, being only slightly greater than the basal metabolism; the appetite is poor and the patients are lethargic. As they gain weight, on an increased diet, the total metabolism rises 50 per cent or more. This is not in any significant degree due to increase in surface area or specific dynamic action of food. 
Type 2: The total metabolism in this type is high before treatment. The patients have a good appetite but are nervous and overactive. As they gain weight, total metabolism increases, but to a less extent than in Type 1. The basal metabolism is about the same in the two types, being about minus 10 in each.

The effect of insulin (commercial and crystalline) in undernutrition was observed. It does not produce any change in total or basal metabolism nor does it affect the rate of weight gain on a constant diet. Its effect seems to be solely to increase appetite.

In obesity the total metabolism is about the same as in the second type of undernutrition. Consequently the caloric output per square meter of surface area is very low. 'On a reduction diet (1,100 to 1,300 calories) there is always a progressive loss of weight. As the patient loses weight the insensible perspiration diminishes, but the basal metabolism usually does not change much.

Malignant Hypertension: The Pre-renal Phase. By Clifford Wilson and Paul Kimmelsteel (introduced by Edwin A. Locke), Boston, Mass.

A study of the clinical and histological features of socalled benign and malignant hypertension has led to the conclusion that cases of malignant hypertension occur without kidney involvement. Such cases lead to a clearer conception. of the disease entity than is obtained from the classical description of Volhard and Fahr.

We believe that the condition commonly known as malignant nephrosclerosis represents only an end stage of the disease. The clinical picture is that of unusually high blood pressure occurring in young subjects and terminating in renal failure. Histologically they show characteristic arterial lesions, namely, productive endarteritis and necrotising arteriolitis in the kidney and other organs, asosciated with focal glomerulonephritis.

Certain cases are here described in which death occurs without renal involvement. From a consideration of the clinical and histological findings we feel that these cases can be separated from the group of benign hypertension. Clinically they show unusually high blood pressure developing in young subjects. Death occurs from extrarenal causes but has a more fulminating character than is seen in benign hypertension. Usually with cerebral manifestations, such as have been termed hypertensive encephalopathy. The characteristic arterial lesions of malignant hypertension are usually present in these cases though less prominent than in the classical picture described by Fahr. We conclude from this clinical and histological study that malignant hypertension is a primary vascular disease in which the renal manifestations occur as a terminal event.

Observations on Associated Tuberculous and Non-tuberculous Pulmonary Lesions. By F. Maturice McPhedran, Philadelphia, Pa.

The association of non-tuberculous bronchopneumonia with various tuberculous pulmonary lesions has been ob- served. Tuberculous lesions have their base on the pleura and rarely invade the cardiophrenic area, where nontuberculous lesions originate and spread along the diaphragm. Extensive pleural effusion and thickening are rare when either of these lesions occurs alone but are common with contiguous tuberculous and non-tuberculous infiltrations. Unusually numerous wide-spread foci of calcification are seen as they heal. The tuberculous element of these associated lesions, even when excavated, tends to heal rapidly and permanently. The non-tuberculous lesion may persist for years as a relapsing bronchopneumonia with persistently negative sputum.

Non-tuberculous bronchopneumonia has been observed in a few cases in association with a uniformly distributed miliary tuberculosis. Of these, three are apparently well except for a persisting bronchopneumonia. The fourth died of a descending apical-caudal tuberculosis after clearing the miliary lesion (postmortem). In all four cases the tuberculous pulmonary lymph nodes were enormously enlarged. In two, non-tuberculous bronchopneumonia and tuberculous nodes were observed before the development of miliary tuberculosis. In all these, and in some other cases, serial observations suggest that the non-tuberculous bronchopneumonia caused hematogenous spread by flooding the nodes rather than by "depressing resistance."

Effects of Alpha-Dinitrophenol on Energy Metabolism, Blood Chemistry and Renal Function: Studies in Obese Subjects. By Maurice Bruger, Cameron V. Bailey and George C. Thosteson (introduced by $H$. $O$. Mosenthal), New York, N. Y.

Nine obese women were studied under basal conditions and every hour for three or four hours after the ingestion of alpha-dinitrophenol ( 3.5 mgs. per kilogram). The respiratory exchange was determined by a modified Tissot method. In the blood sugar, lactic acid, acetone bodies, urea nitrogen, nonprotein nitrogen, free and ester cholesterol and chlorides were determined. In the urine urea nitrogen and nonprotein nitrogen were estimated. The basal metabolic rate, the combustion of protein, fat and carbohydrate, the urea ratio and the urea clearance were obtained by calculation from the above data.

The augmented metabolism after dinitrophenol was accompanied by small but appreciable increases in mouth temperature, respiration and pulse rate; the fuel mixture was definitely altered; carbohydrate and fat combustion were increased while protein catabolism was significantly diminished. Appreciable quantities of carbohydrate were burned, even though under control conditions carbohydrate was absent from the fuel mixture because of previous dietary restrictions.

The blood sugar, lactic acid and acetone bodies were increased; the blood chlorides and urinary nitrogen were decreased; the blood urea nitrogen, nonprotein nitrogen, free and ester cholesterol remained practically unchanged. The urea ratio and urea clearance showed little or no change in renal function. 
Further Observations on the Leucocytic Response Induced by the Intramuscular Injection of Liver Extract. By JoHN H. Powers, with the assistance of Cynthia VANDoREN, Cooperstown, N. Y.

Observations on the degree and character of the leucocytic response induced by the intramuscular administration of liver extract to 7 normal subjects and to 3 surgical patients with infection have been described and presented in graphic form.

The normal individuals were divided into two groups. To the first of these $3 \mathrm{cc}$. of liver extract were given at 9 o'clock in the morning. The leucocytic response was neutrophilic in character, reached its peak in 6 hours and was composed of a relatively greater increase (235 per cent) in the young forms than in the mature cells (96 per cent). The number of juveniles increased from zero to 270 per cu. $\mathrm{mm}$.

There were 3 normal subjects in the second group who received the same amount of extract at 5 o'clock in the morning. The total white cells doubled, the neutrophils increased 169 per cent and the band forms, 370 per cent. The juveniles rose from zero to 400 per cu. mm. The peak of the rise again occurred 6 hours after the injection. The results suggest that the leucocytosis induced by the intramuscular administration of liver extract to normal individuals is due either to direct or indirect stimulation of the bone marrow.

Three surgical patients with sepsis were given liver extract intramuscularly. In each case the leucocytic count was low before the injections were started, and a well marked leucocytosis occurred thereafter. The response was entirely neutrophilic in character.

A Study of the Calcium, Phosphorus, and Energy Exchange in a case of "Pituitary Basophilism." By R. H. Freyberg (by invitation), L. H. Newburgh, PaUL S. BARker, R. L. Grant (by invitation) and Fredrick A. Coller (by invitation), Ann Arbor, Mich.

The calcium, phosphorus and energy exchange was studied over a long period of time in a 19-year-old male, who clinically exhibited the syndrome of pituitary basophilism (with marked skeletal demineralization and obesity) and at autopsy showed an anterior-lobe pituitary adenoma of incompletely differentiated basophil cell type.

The serum calcium was slightly elevated, the serum phosphorus distinctly low. On a low calcium diet the urinary calcium was rather high, and the calcium balance negative. When the diet was made rich in calcium the urinary calcium remained unchanged, the fecal calcium became great, and the balance remained slightly negative. Administration of large amounts of $\mathrm{CaHPO}$, was attended by huge fecal excretion of calcium, unchanged urinary calcium and only a slight retention of calcium. Irradiated ergosterol, haliver oil, yeast, $\mathrm{NH}_{4} \mathrm{Cl}, \mathrm{HCl}$ and $\mathrm{CaCl}_{2}$ were of little or no benefit. When calcium gluconate was injected intravenously much of the calcium was retained with sufficient phosphorus to form $\mathrm{Ca}_{3}$ $\left(P_{4}\right)_{2}$. Study of the calcium and phosphorus exchange did not indicate abnormal parathyroid function but showed insufficient absorption of calcium.

Undernutrition caused weight loss exactly as predicted for normals, thus indicating normal energy exchange and the absence of any unusual metabolic feature as the cause of this patient's obesity.

The Response of the Systolic Blood Pressure to Cold and to Mental Stress in Essential Hypertension, Duodenal Ulcer, Vasomotor Instability, Psychoneurosis and Normal Controls. By Robert Sterling Palmer, Boston, Mass.

The systolic blood pressure in the left brachial artery has been studied, noting spontaneous variations, response to mental stress and response following immersion of the opposite hand in cold water for one minute. Patients with hypertension, patients with duodenal ulcer, apparently normal people with some signs or symptoms of vasomotor instability, and entirely normal controls have been compared. Spontaneous variations are greater in patients with essential hypertension than in normal controls, in patients with functional nervous disorders or in patients with duodenal ulcers. Seventy-six experiments on twenty-three patients with essential hypertension show that the response of the systolic blood pressure to mental stress, while not quite as great as, is, nevertheless, comparable to the response to cold. Both are greater than in entirely normal controls. Patients with duodenal ulcer, patients with functional nervous disorders (functional indigestion, attempted suicide, psychoneurotic vomiting) and patients with vasomotor instability commonly show a marked response of the systolic blood pressure to cold but comparatively little to mental stress. Entirely normal controls appear to have a moderate, but relatively greater, response to mental stress compared to the response to cold. Observations on one case of coarctation of the aorta and on one case of cortical adenoma show a marked response to cold but a relatively smaller response to mental stress.

It is suggested: (1) that immersion of the hand in cold water is a potent stimulus to the autonomic nervous system; (2) that the degree of systolic blood pressure response may indicate the irritability of the autonomic nervous system as an unconditioned response; and (3) that a characteristic of essential hypertension is not an unduly irritable autonomic nervous system, such as is found also in cases of vasomotor instability, functional nervous disorders and duodenal ulcer, but that the vascular response is especially conditioned to mental stress.

Clinical Glycosuria Associated with Biliary Obstruction. By Herbert Pollack and (by invitation) Herman LANDE, New York, N. Y.

The experimental investigations of the functions of the liver have demonstrated the importance of this organ in the carbohydrate cycle. In hepatectomized animals the injection of glucose at a rate greater than its immediate usefulness to the organism produces hyperglycemia and 
glycosuria. When insufficient glucose is supplied hypoglycemia occurs.

The application of these physiological concepts to clinical medicine is demonstrated in the following case histories. The first patient had colicy epigastric pains for one month and acholic stools the last five days. Forty-five units of insulin were required with a diet of 160 grams carbohydrate to control glycosuria. Cholecystectomy and removal of stones from the common duct were carried out. Severe postoperative hypoglycemia followed. Glucose tolerance was normal three weeks later. Case number 2 was given 90 units of insulin with a diet of 250 grams of carbohydrate. Four weeks after cholecystectomy glucose tolerance was normal. Case number 3 was that of a man suffering from a carcinoma of the head of the pancreas with common duct obstruction. Ninety units of insulin were required with a diet of 200 grams carbohydrate to prevent glycosuria. Obstruction was relieved by cholecystgastrostomy. Postoperative hypoglycemia followed in spite of continuous intravenous glucose infusion. The icterus cleared up. Pancreatic obstruction increased, as evidenced by rising blood amylase. Glucose tolerance test was normal three weeks later.

\section{The Effect of Prolonged Dietary Restriction on Patients}

With Cardiac Weakness. By S. H. Proger and (by invitation) H. Magendantz, Boston, Mass.

Physiologists have demonstrated that prolonged dietary restriction (loss of approximately 10 per cent body weight in about six weeks) commonly produces the following results: Striking lowering of oxygen consumption (about 30 per cent), significant slowing of the pulse rate, lowering of blood pressure and lowering of fluid intake and output. If such changes occur without apparent harmful effects then their production seems eminently desirable in patients with cardiac weakness. We have, therefore, studied the effect on such patients, of dietary restriction with a loss of 10 to 15 per cent in body weight over four to six weeks after adequate preliminary control. The following features were studied: oxygen consumption, respiratory quotient, pulse rate, blood pressure, velocity of blood flow, cardiac output, venous pressure, vital capacity, respiratory rate, respiratory minute volume, blood cholesterol, blood glucose tolerance, fluid intake and output, nitrogen intake and output, chloride excretion, response of pulse and respiration to exercise on bicycle ergometer and incidental clinical changes. Daily observations were made over a period of eight to ten weeks, thereafter at two to four week intervals.

In four patients (3 normal weight and one underweight) thus far completed the results showed that a condition can be thus artificially produced in which the work of the heart approaches a minimum. Among other things there was distinct lowering of caloric and water exchange, drop in blood pressure, pulse rate, and cardiac output and increase in vital capacity and capacity for work.
-If it is self-evident that the weight of an obese patient with cardiac weakness should be reduced, it appears just as self-evident that in patients with heart disease of normal and even low weight it should be reduced, since the theoretic as well as actual benefits are even more striking in the latter group.

Studies on Microbic Dissociation of Micrococcus Tetragenus Obtained From a Nonfatal Case with Septicemia, Purulent Arthritis and Meningitis. By HoBART A. Reimann, Minneapolis, Minn.

The organism when first isolated grew in clusters and formed white colonies resembling a slowly growing staphylococcus. Upon aging on agar the colonies became yellow, developed yellow daughter and white daughter colonies, and later translucent colonies appeared. These colony forms seemed to correspond with the " $M$," " $S$ " and " $R$ " phases involved in microbic dissociation of other organisms. But later a shell-pink and an orange-brown form were also induced. Cocci from the yellow colony formed large tetrads, the white formed tetrads or clusters, and the translucent colony cocci were minute and markedly pleomorphic. The 3 forms would ordinarily be mistaken for different, unrelated organisms except that reversion from one form to another could be induced by appropriate methods in vitro and in vivo. Organisms from the yellow, white and translucent colonies differed sharply in their biological reactions as regards sugar fermentation, gelatin liquefaction, pigment production, hemolysis and resistance to numerous adverse conditions. The pink and brown forms behaved generally like the white. The five dissociant forms characterized by such different morphologic characteristics provide a unique opportunity for observations in dissociative phenomena. The pigments of the yellow, pink and brown colonies belonged to the carotinoid group and appeared to be chemical isomers, differing from one another spectroscopically.

Immune sera prepared with the 5 varieties were specific for the respective homologous variety. The sera agglutinated occasional strains from other sources indicating the existence of type specificity as well. Surprisingly, the sera prepared from the dissociant forms agglutinated specifically the corresponding dissociants of the type-specific strains from other sources.

Reticulocytosis In Non-Hemolytic Jaundice. By LEON Schiff and (by invitation) Murray L. Rich, Cincinnati, Ohio.

In a series of over thirty-five cases of regurgitation jaundice (obstructive and toxic or infective hepatic types) a moderate persistent reticulocytosis was frequently observed. In an attempt to explain the underlying mechanism intravenous injections of bilirubin and bile salts (decholin) and intramuscular injections of blood from jaundiced individuals were given to normals and to patients with anemia and the haematological effects studied. 
The Prognostic Significance of the Icteric Index in Lobar Pneumonia. By Gerald S. Shibley and (by invitation) W. W. WADDELL, Cleveland, Ohio.

Considerable difference of opinion exists in regard to the prognostic significance of jaundice in pneumonia. Although many clinical observers have felt that jaundice is a grave finding, the few references to be found in the literature are equivocal. In the present study, which has included nearly 200 cases of lobar pneumonia, the relationship of the icteric index to mortality has been investigated. Our results show that the death rate is proportional to the height of the icteric index. If the index is under 10 , the mortality rate is slightly below 30 per cent; if over, it is approximately 60 per cent. Such factors as type of pneumococcus, infection of blood stream, or age do not influence this graver prognostic significance of the higher indices. The definite value of specific serum therapy in Type I infections is brought out by the fact that although the death rate in untreated cases, with an index of 10 or over, was 57 per cent, it was only 10 per cent in such cases receiving serum.

Iron Retention in Hypochromic Anemia. By W. M. Fowler (by invitation), AdELAIDE BARER (by invitation) and Fred M. Smith, Iowa City, Iowa.

Studies of iron balance have been carried out in forty patients in an attempt to ascertain the amount of iron retained and the factors influencing the retention of iron and formation of hemoglobin in hypochromic anemia.

Those patients whose anemia was idiopathic in origin and those in whom it was secondary to chronic blood loss showed no appreciable difference in retention of iron.

With a normal iron intake (12 $\mathrm{mgm}$. per day derived from food) less iron was retained by those patients with an achlorhydria than by those with a normal or low gastric acidity. The administration of $\mathrm{HCl}$ and pepsin did not increase the retention of iron under these conditions.

With the administration of iron ( $500 \mathrm{mgm}$. per day) in the form of ferric ammonium citrate a surprisingly large amount was retained. This retention was not appreciably influenced by achlorhydria nor by the administration of $\mathrm{HCl}$.

The addition of a small amount of copper to the medicinal iron seemed to decrease the amount of iron retained, although the hemoglobin regeneration was more rapid and the percentage of the iron that was utilized as hemoglobin was greater.

The Influence of Castration on Stimulation of the Thyroid by Pituitary Thyreotropic Hormone. By PAUL StaRR, Chicago, Ill.

During studies of pituitary thyreotropic action in guinea-pigs (begun in 1931 and reported in 1932 and 1934), a fairly uniform response in the form of elevated metabolic rates has been found after daily subcutaneous injections of $0.1 \mathrm{cc}$. of a pituitary solution prepared by Parke, Davis and Company. In a group of seven female animals, after the fifth daily injection the basal metabolic rate ranged from +35 to +63 per cent.
In five female animals previously castrated, after the fifth daily injection the metabolic rate ranged from -3 to +17 per cent. In four other animals the rate rose rapidly but the rise was delayed in onset. In one animal castrated after 4 daily injections, having a metabolic rate elevated +35 per cent, the rate dropped during continued injections to \pm 0 per cent five days after the operation; while the control, continuously injected animal continued to have an elevated rate of +45 per cent for 23 days and then declined as has previously been shown.

Histologic study of the uncastrated animals shows the usual marked hyperplasia of the thyroid. The thyroids of the castrated animals similarly treated show no hyperplasia, or a peculiar engorgement is found if the metabolic rate has risen. An attempt to correlate this prevention of the thyreotropic action with release of gonadotropic pituitary hormone by castration is being made by assays of the blood. In a normal man weighing 175 pounds the same solution raised the metabolic rate in a few days from -5 to +15 per cent. In a castrated woman weighing 93 pounds similar dosage raised the rate from +2 to +7 per cent in two weeks.

Extension of these studies in other animals and humans is being carried on intensively. It is thought that this is a demonstration of an endocrine thyroid protective or inhibiting mechanism.

The Effect of Vitamin B upon Hematopoiesis in the Rat. By Frank H. Bethell (by invitation) and Cyrus C. Sturgis, Ann Arbor, Mich.

The prevention and cure of milk anemia of the rat does not depend exclusively upon the mineral content of the diet. A supplementary action to iron and copper is exerted by the vitamin B complex. This property, under the conditions of the present studies, is not possessed by either vitamins $B_{1}$ or $B_{2}$ but is contained within the $B_{4}$ fraction.

One of the earliest changes observed during treatment with iron and copper supplements is a transition of the anemia from a microcytic to a macrocytic type. Upon the addition of the vitamin $B_{4}$ fraction the mean erythrocyte diameter rapidly becomes normal. When supplementary $\mathrm{B}_{\mathbf{4}}$ fraction together with iron and copper is given throughout the course of treatment, temporary macrocytosis does not occur.

In the cure of the milk anemia of the rat vitamin B, fraction apparently exerts an influence both upon the synthesis of hemoglobin and the maturation of the erythrocyte.

The Development of Pneumococcic Antibodies in Children. By W. D. SutLIFF and (by invitation) JонN A. V. Davies, Chicago, Ill.

The appearance of serum immune bodies and other immune reactions with increasing age, without apparent infection by the corresponding microrganisms, has given rise to two hypotheses: (1) subclinical infection and (2) physiological development. The first of these, or contact between host and microorganism without disease, 
may be investigated in man during a period when immune phenomena are being established, and this has been done in the study to be reported. The study is facilitated by the ready identification of type specific pneumococcic strains and their corresponding antibodies, and knowledge that such antibodies develop most often about the age of 2 years. Contacts with pneumococci and the appearance of blood bactericidal power for certain strains were observed in 9 infants from 5 to 21 months of age during a period of 5 winter months. Three infants developed antibodies for Type II pneumococci. None were observed to carry Type II pneumococci in their pharynges during this period. Data were assembled as to the health of all the infants and as to the incidence, type and pathogenicity of the pneumococcic strains that were encountered. It is concluded that neither true infection nor a carrier state of as long as one week are necessary to the appearance of Type II pneumococcic bactericidal action of the blood.

\section{The Effect of Iodine on Certain Aspects of Cholesterol} Metabolism. By KenNeTh B. TuRner and (by invitation) Frederick H. Shildito, New York, N. Y.

Thoracic duct fistulae were produced in otherwise normal dogs and the chyle cholesterol determined after feeding cream and cream plus cholesterol. Thorough iodization of another group of dogs did not prevent the rise normally observed in chyle cholesterol after ingestion of cream and cholesterol. It was concluded that $\mathrm{KI}$ had no effect upon the absorption of cholesterol.

$\mathrm{KI}$ was given to rabbits previously fed with cholesterol over a long period and showing a markedly elevated cholesterol in the blood. A sharp rise in blood cholesterol occurred that disappeared when KI was stopped. This rise took place regardless of the presence or absence of the thyroids. The previously reported action of $\mathrm{KI}$ in preventing a rise in blood cholesterol when fed concurrently with cholesterol was shown to be of a transient nature.

An attempt was made to determine whether $\mathrm{KI}$ was capable of mobilizing tissue cholesterol. Rabbits were fed cholesterol for several months. One-third of the animals were killed and the liver cholesterol determined. Of the surviving rabbits half were given $\mathrm{KI}$ for a further period, and the other half used as controls. After two months all the animals were killed and the liver cholesterol determined.

The Phase Angle as a Test for Thyroid Dysfunction. By FrankLIN D. Johnston (introduced by Frank N. Wilson), Ann Arbor, Mich.

Following the method described by Brazier,1, 2 we have measured the phase angle of a number of normal individuals and patients having hyperthyroidism or myxedema.

For normal adult males and females the phase angles

1 M. A. B. Brazier. Institution of Elect. Engineers, 1933, 73: 204.

2 M. A. B. Brazier. Lancet, 225: 742, Sept. 30, 1933. fall into two distinct groups according to sex. For each sex there is considerable individual variation from the mean of the group, but the mean values agree closely with the results of Brazier. Patients with hyperthyroidism show a definite decrease in the phase angle usually outside the limits of normal variation and occasionally nearly 50 per cent below the average normal value for the patient's sex. Following thyroidectomy there appears to be no change in the phase angle until a period of approximately three weeks has elapsed. After this time, the angle increases gradually until it is within normal limits. After oral administration of thyroid substance no lowering of the phase angle has been observed until the patient has been taking the drug for at least a month. The phase angles obtained from a few patients with myxedema, before thyroid therapy was instituted, were within normal limits.

The Occurrence of Coronary Air Embolism in Artificial Pneumothorax. By T. M. Durant ${ }^{1}$ (introduced by Frank N. Wilson), Ann Arbor, Michigan.

This paper is based on the observation of a case in which, following air embolism complicating attempted artificial pneumothorax, a series of exceedingly interesting electrocardiographic changes was observed. The case was predominantly one of unilateral pulmonary tuberculosis and congenital pulmonary stenosis, in which an electrocardiogram prior to treatment had been negative except for right axis deviation. A series of electrocardiograms, following the acute collapse due to the air embolism, showed findings and progressive changes in both the initial and final deflections of the ventricular complex typical of myocardial infarction. The first curve was taken within three hours of the accidents. The changes noted persisted for approximately a year, at the end of which time there was a return to the type of curve observed before the infarction.

The general subject of air embolism is discussed, and reasons are given for attributing the incident described to involvement of the coronary vessels in the embolic process.

A Sphygmographic Method for the Study of Systolic and Diastolic Blood Pressure in Dogs: Illustrated with Curves from Normal and Hypertensive Animals. By J. EDwIN Wood, JR. and (by invitation) JAMES CASH, University, Virginia.

Methods for the study of systolic and diastolic blood pressure in the unanesthetized dog have been generally unsatisfactory. With one exception (Cash) long time experiments showing both systolic and diastolic values are not available in the literature. The purpose of this paper is to describe a modification of the Kolls-Cash method which permits repeated systolic and diastolic readings on the unanesthetized dog and to illustrate the procedure with curves made up of numerous determinations on normal and hypertensive animals.

\footnotetext{
1 Department of Internal Medicine, University of Michigan Medical School.
} 
A compound lever of special design (Kolls) is arranged with a mercury column, a pneumatic cuff for the dog's leg, and a brass control valve as in the usual sphygmographic assembly. The original Erlanger rubber bulb is difficult to obtain and the more recent Erlanger sphygmoscope has been tried and found to be unsatisfactory in the lower diastolic ranges. These difficulties have been obviated by the use of a metal pressure bell carrying a heavy piece of automobile tubing as membrane between the cuff and lever systems. This simple modification allows sensitive and accurate response of the compound lever at all blood pressure levels. The accuracy of the method is supported by the original maximum-minimum valve experiments of Kolls and Cash as well as by our own recent observations. A simple check with simultaneous auscultatory and sphygmographic records on humans is convincing.

Eight dogs have been subjected to several procedures with repeated blood pressure observations before and after operation. In addition to the blood pressures, twenty-four hour water intake, output and specific gravity and blood nonprotein nitrogen determinations have been recorded at intervals.

The following table indicates operative procedure, duration of study and result. From 100 to 160 blood pressure determinations have been made on each animal.

\begin{tabular}{|c|c|c|c|c|c|c|}
\hline \multirow{2}{*}{ Dog } & \multirow{2}{*}{ Operation } & \multirow{2}{*}{$\mid \begin{array}{c}\text { Dura- } \\
\text { tion } \\
\text { of } \\
\text { study }\end{array}$} & \multicolumn{2}{|c|}{$\begin{array}{c}\text { Before } \\
\text { operation }\end{array}$} & \multicolumn{2}{|c|}{$\begin{array}{c}\text { After } \\
\text { operation }\end{array}$} \\
\hline & & & $\begin{array}{l}\text { Mean } \\
\text { systolic }\end{array}$ & $\mid$\begin{tabular}{c|} 
Mean \\
dias- \\
tolic
\end{tabular} & $\left|\begin{array}{c}\text { Mean } \\
\text { systolic }\end{array}\right|$ & $\begin{array}{c}\text { Mean } \\
\text { diag- } \\
\text { tolic }\end{array}$ \\
\hline $\begin{array}{l}\text { C-1 } \\
\text { C-15 } \\
\text { C-9 } \\
\text { C-11 }\end{array}$ & $\begin{array}{l}\text { Goldblatt clamps } \\
\text { Goldblatt clamps } \\
\text { Goldblatt clamps } \\
\text { Subtotal }\end{array}$ & \begin{tabular}{|c|} 
Months \\
7 \\
13 \\
13
\end{tabular} & \begin{tabular}{|l|}
167.4 \\
160.9 \\
148.0
\end{tabular} & \begin{tabular}{|l|}
71.9 \\
52.85 \\
54.0
\end{tabular} & $\begin{array}{l}200.0 \\
185.4 \\
215.3\end{array}$ & \begin{tabular}{|c|}
111.3 \\
79.95 \\
96.4
\end{tabular} \\
\hline C-2 & $\begin{array}{l}\text { nephrectomy } \\
\text { Subtotal }\end{array}$ & 15 & 175.1 & 63.5 & 186.4 & 76.3 \\
\hline C-6 & $\begin{array}{l}\text { nephrectomy } \\
\text { Partial renal }\end{array}$ & 15 & 172.2 & 79.3 & 179.8 & 87.6 \\
\hline C-8 & $\begin{array}{l}\text { artery ligation } \\
\text { Partial renal }\end{array}$ & 15 & 160.0 & 61.2 & 193.7 & 79.2 \\
\hline C-3 & $\begin{array}{l}\text { artery ligation } \\
\text { Partial renal }\end{array}$ & 15 & $\mid 132.9$ & 60.9 & 133.7 & 66.9 \\
\hline & artery ligation & 15 & 150.5 & 55.3 & 198.0 & 87.1 \\
\hline
\end{tabular}

Significant elevations in systolic and diastolic blood pressure have occurred in six of the eight animals. Diastolic readings have been less variable than systolic and are essential to the study of hypertension in dogs. The most striking blood pressure rise has taken place when renal ischemia has been produced by the application of Goldblatt clamps to the renal arteries. 